\title{
Crystallographic-magnetic correlations in single-crystal haemo-ilmenite New evidence for lamellar magnetism
}

\author{
Journal Article \\ Author(s): \\ Robinson, P.; Heidelbach, F.; Hirt, Ann Marie (D); McEnroe, S.A.; Brown, L.L. \\ Publication date: \\ 2006-04 \\ Permanent link: \\ https://doi.org/10.3929/ethz-b-000024971
}

Rights / license:

In Copyright - Non-Commercial Use Permitted

Originally published in:

Geophysical Journal International 165(1), https://doi.org/10.1111/j.1365-246X.2006.02849.x 


\title{
Crystallographic-magnetic correlations in single-crystal haemo-ilmenite: new evidence for lamellar magnetism
}

\author{
P. Robinson, ${ }^{1,4}$ F. Heidelbach, ${ }^{2}$ A. M. Hirt, ${ }^{3}$ S. A. McEnroe ${ }^{1}$ and L. L. Brown ${ }^{4}$ \\ ${ }^{1}$ Geological Survey of Norway, N-7491, Trondheim, Norway.E-mail: peter.robinson@ngu.no \\ ${ }^{2}$ Bayerisches Geoinstitut, Universität Bayreuth, D95440, Bayreuth, Germany \\ ${ }^{3}$ ETH, Zurich, Switzerland \\ ${ }^{4}$ Department of Geosciences, University of Massachusetts, Amherst, MA 01003, USA
}

Accepted 2005 October 17. Received 2005 August 26; in original form 2005 April 14

\begin{abstract}
SUMMAR Y
17 single crystals were identified by electron backscatter diffraction (EBSD) and isolated from coarse massive haemo-ilmenite ore from South Rogaland, Norway. These were studied using the EBSD results, natural remanent magnetization (NRM), and anisotropy of magnetic susceptibility (AMS), to gain a better understanding of angular relationships between crystallographic axes and magnetic properties of haemo-ilmenite in relation to lamellar magnetism. Electron microprobe analyses gave the following average end-member compositions for ilmenite host: 21.1 per cent $\mathrm{MgTiO}_{3}, 73.7 \mathrm{FeTiO}_{3}, 0.5 \mathrm{MnTiO}_{3}, 4.3 \mathrm{Fe}_{2} \mathrm{O}_{3}, 0.2 \mathrm{Cr}_{2} \mathrm{O}_{3}$ and $0.3 \mathrm{~V}_{2} \mathrm{O}_{3}$; and for the coarsest $(\sim 3 \mu \mathrm{m})$ haematite exsolution lamellae: $3.5 \mathrm{MgTiO}_{3}, 22.4 \mathrm{FeTiO}_{3}, 71.4 \mathrm{Fe}_{2} \mathrm{O}_{3}$, 1.6 $\mathrm{Cr}_{2} \mathrm{O}_{3}, 1.0 \mathrm{~V}_{2} \mathrm{O}_{3}$ and $0.1 \mathrm{Al}_{2} \mathrm{O}_{3}$, making this sample the most Mg- and Cr-rich haemoilmenite studied in the province, but with similar element fractionations between the coexisting phases. TEM work on similar material suggests the presence of much thinner exsolution down to $1-2 \mathrm{~nm}$.

The EBSD, NRM and AMS results from 12 out of 17 crystals indicate a good agreement between the orientation of crystallographic axes, NRM direction and principal axes of the magnetic susceptibility ellipsoid, with the NRM located in the (0001) basal plane [NRM $\wedge$ $\left.(0001)<6.5^{\circ}\right]$ and the crystallographic $\mathbf{c}$ axis quasi-parallel to the minimum axis of the susceptibility ellipsoid [ $\mathbf{c}^{\wedge} \mathrm{k} 3<13.5^{\circ}$ ]. In addition, in 10 of these 12 crystals, the remanent magnetization vector is parallel or nearly parallel to the positive direction of a crystallographic $\mathbf{a}$ axis [NRM $\wedge \mathbf{a}<20^{\circ}$ ], hence parallel to a principal magnetic moment direction in haematite as determined by Besser et al., and not parallel to the spin-canted direction of end-member haematite. This is consistent with a basic property of lamellar magnetism, where the magnetic moment is parallel to the principal moments (sublattice magnetization directions) in haematite. Relationships in three additional crystals with NRM $\wedge \mathbf{a}=22^{\circ}-33^{\circ}$, only two with good agreement, can be interpreted as consistent with having a magnetic vector quasi-parallel to the spin-canted direction of haematite.
\end{abstract}

Key words: anisotropy of magnetic susceptibility, electron backscatter diffraction, haematite, haemo-ilmenite, lamellar magnetism, natural remanent magnetization.

\section{INTRODUCTION}

According to the lamellar magnetism hypothesis (McEnroe et al. 2001a, 2002; Harrison \& Becker 2001; Robinson et al. 2002, 2004) composite $\mathrm{Fe}^{2+}-\mathrm{Fe}^{3+}$ contact layers between ilmenite Ti layers and $\mathrm{Fe}^{3+}$ haematite layers on opposite sides of an ilmenite lamella have parallel magnetic moments in the basal (0001) plane. These are weaker than the principal magnetic moments of $\mathrm{Fe}^{3+}$ layers of haematite, but are antiferromagnetically coupled to them. So long as two ilmenite lamellae are magnetically in phase, there is an odd number of haematite layers between them, so that the magnetic moment of one haematite cation layer is non-self-cancelling, leading to a magnetic moment antiparallel to the moments of the contact layers. The combination of the magnetic moments of the two contact layers minus that of one haematite layer $\left(2 M C_{\mathrm{L}}-1 M H_{\mathrm{R}}\right.$ or $2 M C_{\mathrm{R}}$ $-1 M H_{\mathrm{L}}$ ) leads to the unique ferrimagnetic structure of lamellar magnetism and a net moment of $\sim 4 \mu \mathrm{B}$ per lamella. Crucial to the arguments in the present paper is that the magnetic moments 
of lamellar magnetism are parallel to the principal magnetic moments (sublattice magnetization directions) within the haematite $\mathrm{Fe}^{3+}$ layers.

A complete introduction to the subject of lamellar magnetism and lamellar magnetic materials is beyond the scope of this paper, and is covered at length in the papers cited above. McEnroe \& Brown (2000) and McEnroe et al. (2001a,b, 2002, 2004b, 2005 ) highlighted the strong magnetic remanence and extreme coercivity of rocks rich in coarsely to finely exsolved members of the haematite-ilmenite series, and their contributions to unusual magnetic anomalies in the Adirondacks, New York, the southwest Swedish granulite region, and the South Rogaland anorthosite province in Norway, all regions cooled $\sim 1$ Gyr ago. These oxides contained a combination of properties including strong natural remanent magnetization (NRM), and high coercivity with median destructive fields from 70 to $>120 \mathrm{mT}$, that could not be explained by antiferromagnetic haematite nor by paramagnetic ilmenite alone. Thermal demagnetization occurs in the range $550^{\circ}-$ $640^{\circ} \mathrm{C}$ expected for Ti-bearing haematite, suggesting haematite is intimately linked to the magnetization. These authors suggested that the properties must somehow be explained by the exsolution itself, particularly since the properties were quite similar, whether the host was haematite or ilmenite. The samples were studied with highresolution transmission electron microscopy (TEM) and also analytical TEM, and exsolution lamellae were shown to go down to a thickness of about 1-2 nm (a unit cell of rhombohedral oxide is $\sim 1.4 \mathrm{~nm}$ ) (McEnroe et al. 2001a, 2002, 2005; Kasama et al. 2004).

Atomic models of haematite-ilmenite interfaces have been developed by Harrison, using Monte Carlo simulations that take into account both electrostatic and magnetic interaction parameters (Harrison \& Becker 2001; Robinson et al. 2002, 2004; Harrison 2006). These simulations showed that the interfaces on the basal plane should be decorated with 'contact layers' one cation thick that are unlike any of the individual layers of haematite and ilmenite. There are two key features of the contact layers in the simulations:

(1) they are magnetically coupled by superexchange to the adjacent haematite $\mathrm{Fe}^{3+}$ layers so that coercivity and thermal stability are similar to haematite and

(2) the magnetic moments of the contact layers are less than the adjacent haematite layers, so they create opposite but unequal magnetic moments and a new kind of ferrimagnetism, which is essentially a kind of defect magnetization, that is not a property of a phase but a property of haematite coupled with its interfaces. Although the discovery of these contact layers was partly based on magnetic interactions, it was soon realized that contact layers can reduce charge imbalance across phase boundaries and may be applicable in general at mineral interfaces (Robinson et al. 2002, 2004, 2006).

The discovery from the simulations initiated discussions about how to build larger models of lamellar magnetic material and how to understand the development of lamellar magnetic material through application of the haematite-ilmenite phase diagram, including effects of pressure and additional components on the phase diagram. The phase diagram, still in a state of flux (McEnroe et al. 2004a, Harrison 2006), indicates that lamellar magnetism forms when there is phase separation of canted-antiferromagnetic haematite (CAF) from paramagnetic ilmenite $(R \overline{3})$. Such separation and the coexistence of these two phases can only occur at a temperature below $525^{\circ} \mathrm{C}$ and the resulting magnetization is considered a chemical remanent magnetization because it is produced by the chemical reaction of exsolution. Once exsolution has taken place, thermal de-

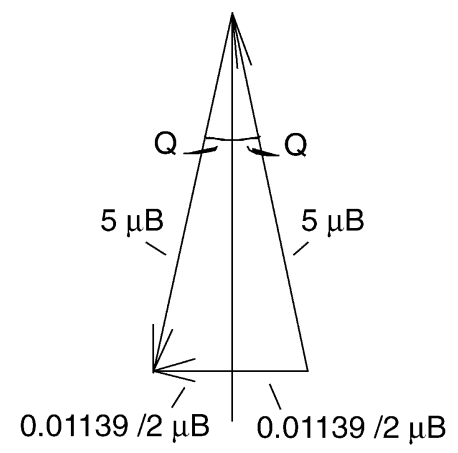

$$
\begin{gathered}
\sin Q=(0.01139 / 2) / 5=0.001139 \\
Q=\arcsin 0.001139=0.0653^{\circ}
\end{gathered}
$$

Figure 1. Geometrical relationships within the (0001) basal plane of haematite used to calculate the spin-canted angle, $Q$, using the calculated saturated ferromagnetic moment per formula unit $(\mathrm{M} \mathrm{pfu})=0.01139 \mu_{B}$. This value was derived from the following: $M_{S}$ haematite $=2.1 \mathrm{kAm}^{-1}$; cell volume of haematite $=5.034 * 5.034^{*} \cos (30)^{*} 13.750=301.761 \AA^{3} ; \mathrm{Z}=$ formula units per unit cell $=6$; 1 Bohr magneton $\left(\mu_{B}\right)$ in $\mathrm{Am}^{2}=9.2741 \mathrm{e}$ -

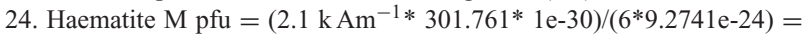
$0.01139 \mu_{B}$.

magnetization experiments indicate stability to temperatures commonly above $580^{\circ} \mathrm{C}$, so long as the lamellar structure and composition are not destroyed. Because the magnetization is inherent in the phase interfaces, it is increased with greater density and decreased size of exsolution. It is also critically dependent on whether the lamellae are magnetically in- or out-of-phase, which can be improved where the (0001) planes are oriented parallel to the magnetizing field during exsolution (Robinson et al. 2004). For this reason, it appears that lamellar magnetic materials with a strong lattice-preferred orientation, also favourably oriented with respect to the magnetizing field, may develop a particularly strong lamellar magnetism (McEnroe et al. 2004b). 'Lamellar magnetism' is still a hypothesis, but one actively being tested. So far, there is no possibility to image the contact layers that are only $0.23 \mathrm{~nm}$ thick. This paper is the first attempt at a test based on geometrical relationships between haemo-ilmenite single crystals and their magnetic properties.

Within pure haematite, the weak magnetic moment is 'spincanted' in the basal plane. Since postulated by Dzialoshinskii (1958), the spin-canted moment is thought to be due to a very small misalignment from perfect antiparallelism of the principal magnetic moments in the basal plane (Fig. 1). Using a saturated magnetization of $2100 \mathrm{~A} \mathrm{~m}^{-1}$ reduced to $0.01139 \mu \mathrm{B}$ per formula unit, and using sublattice magnetizations of $5 \mu \mathrm{B}$ for the $\mathrm{Fe}^{3+}$ in each octahedral layer, the deviation of the sublattice magnetizations from being perfectly antiparallel calculates to $2 \times 0.06529^{\circ}=0.13058^{\circ}$ (Fig. 1, see also Morrish 1994, table 4.4). The spin-canted magnetization of haematite thus must be perpendicular to the average of the principal magnetic moments in the basal plane of the haematite layers. End-member haematite undergoes a Morin transition at 263 $\mathrm{K}$, where the sublattice magnetizations move from parallel to the basal plane to perfectly parallel to the $\mathbf{c}$ axis, at which point spincanted magnetization disappears. Some samples still retain a very weak magnetization, which has commonly been described as a 'defect moment' caused by unidentified chemical or structural defects in the lattice. Because this defect moment may add something to the saturated magnetization, $M_{s}$, above the Morin transition as well as 


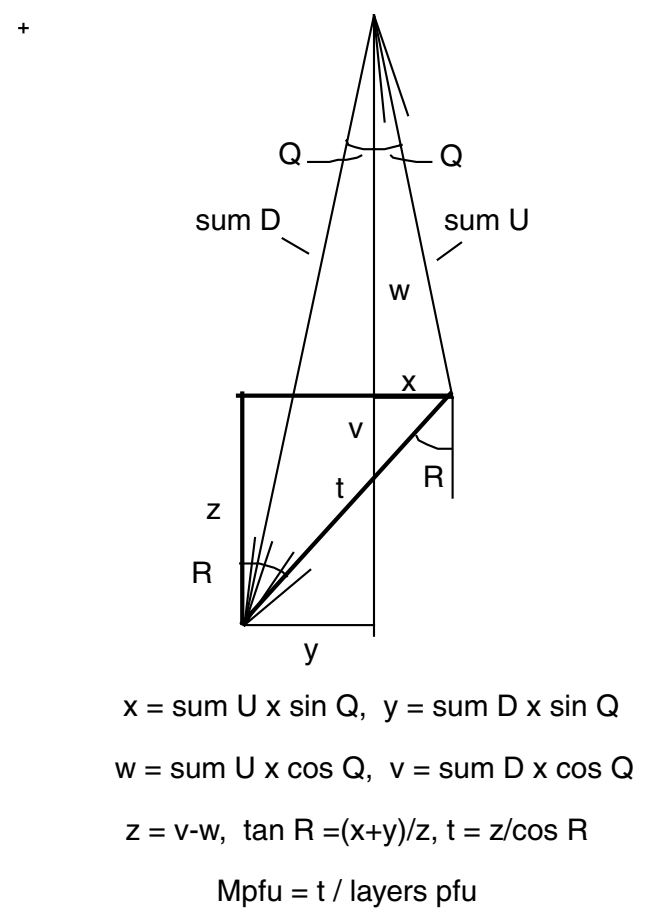

Figure 2. Geometrical relationships within the (0001) basal plane of model lamellar magnetic ilmeno-haematite used to calculate the spin-canted moment of lamellar magnetism from the sum of up (U) and down (D) moments of haematite layers as well as in-phase and out-of-phase contact layers of ilmenite exsolution lamellae. The models assume the same spin-canted angle $\mathrm{Q}$ for individual layers as for haematite. $\mathrm{t}$ is the net moment per formula unit ( $\mathrm{M} \mathrm{pfu}$ ) for lamellar oxide, and $\mathrm{R}$ is the resultant angle of spin-canted lamellar magnetism (see Table 1). cause an imbalance in the sublattice magnetizations, calculation of the spin-canted angle from the $M_{s}$ of haematite as indicated above, may be imprecise. Such a defect moment, like the ferrimagnetic moment of lamellar magnetism, would be parallel to the sublattice magnetizations, but is likely too weak to be an important contributor to the magnetizations in the materials considered here. The Morin transition is suppressed by Ti substitution in haematite and has not been observed in these lamellar magnetic materials.

In the case of natural material containing both spin-canted haematite and lamellar magnetism, we expect the natural magnetization to be neither parallel nor perpendicular to the principal magnetic moments of the haematite layers, but at an oblique angle representing a vector sum of the two components. The theory of such combinations has been tested using Fig. 2 and illustrated here in Table 1. Where the lamellar magnetism is relatively strong and especially where the host is ilmenite, the vector sum is nearly parallel to the principal moments, and only deviates substantially when the strength of the lamellar magnetism is weak.

In addition to these considerations, what follows is heavily dependent on a determination made by Besser et al. (1967, see also Morrish 1994, pp. 101-104) on pure haematite. Using magneticresonance spectra, they were able to show that the principal magnetic moments of the sublattices in haematite are parallel $(+$ or - ) to one of the three crystallographic a axes $(\mathbf{a 1}, \mathbf{a 2}, \mathbf{a 3})$, and that the spin-canted magnetic moment in haematite is perpendicular to one of the three crystallographic a axes (Fig. 3). These observations led us to conclude that, if we could show that the magnetic moment of single-crystal rhombohedral oxide magnetic material was parallel or nearly parallel to a crystallographic a axis, this would strongly support lamellar magnetism, whereas if the moment were 90 degrees from a crystallographic a axis, then an explanation involving the spin-canted magnetization of haematite would have to be considered.

Table 1. Calculated angles and moments of spin-canted lamellar magnetism. Calculations are based on lamellar models XIIA-XIID of Robinson et al. (2004) and the angular relationships in Fig. 2. Note that R is close to zero for high proportions of in-phase lamellae, and only reaches large angles when lamellar magnetism is very weak.

\begin{tabular}{lrrrrr}
\hline Model & Layers pfu & $\begin{array}{r}\text { Fraction of in-phase } \\
\text { Lamellae }\end{array}$ & R in degrees & $\begin{array}{r}\text { Intensity } \\
\text { M pfu in } \mu \mathrm{B}\end{array}$ & $\begin{array}{r}\text { Intensity } \\
\text { /Haematite }\end{array}$ \\
\hline Haematite & 2 & 0.0000 & 90.0000 & 0.01139 & 1.00 \\
XIIA & 36 & 1.0000 & 0.3663 & 1.36603 & 119.95 \\
XIIB & 36 & 0.6670 & 0.5495 & 0.91071 & 79.97 \\
XIIC & 36 & 0.3330 & 1.0989 & 0.45542 & 39.99 \\
XIID & 36 & 0.0000 & 90.0000 & 0.00873 & 0.77 \\
XIIC & 36 & 0.3330 & 1.0989 & 0.45542 & 39.99 \\
XIIC+XIID & 72 & 0.1667 & 2.1970 & 0.22783 & 20.01 \\
XIIC+2XIID & 108 & 0.1111 & 3.2935 & 0.15203 & 13.35 \\
XIIC+3XIID & 144 & 0.0833 & 4.3876 & 0.11417 & 10.03 \\
XIIC+4XIID & 180 & 0.0667 & 5.4784 & 0.09148 & 8.03 \\
XIIC+9XIID & 360 & 0.0333 & 10.8585 & 0.04636 & 4.07 \\
XIIC+14XIID & 540 & 0.0222 & 16.0520 & 0.03159 & 2.77 \\
XIIC+19XIID & 720 & 0.0167 & 20.9887 & 0.02438 & 2.14 \\
XIIC+24XIID & 900 & 0.0133 & 25.6199 & 0.02020 & 1.77 \\
XIIC+29XIID & 1080 & 0.0111 & 29.9185 & 0.01751 & 1.54 \\
XIIC+34XIID & 1250 & 0.0095 & 33.8760 & 0.01579 & 1.39 \\
XIIC+44XIID & 1620 & 0.0074 & 40.8002 & 0.01337 & 1.17 \\
XIIC+54XIID & 1980 & 0.0061 & 46.5332 & 0.01203 & 1.06 \\
XIIC+64XIID & 2340 & 0.0051 & 51.2690 & 0.01120 & 0.98 \\
XIIC+74XIID & 2700 & 0.0044 & 55.1968 & 0.01064 & 0.93 \\
XIIC+84XIID & 3060 & 0.0039 & 58.4782 & 0.01025 & 0.90 \\
XIIC+104XIID & 3780 & 0.0032 & 63.5956 & 0.00975 & 0.86 \\
XIID & 36 & 0.0000 & 90.0000 & 0.00873 & 0.77 \\
\hline
\end{tabular}




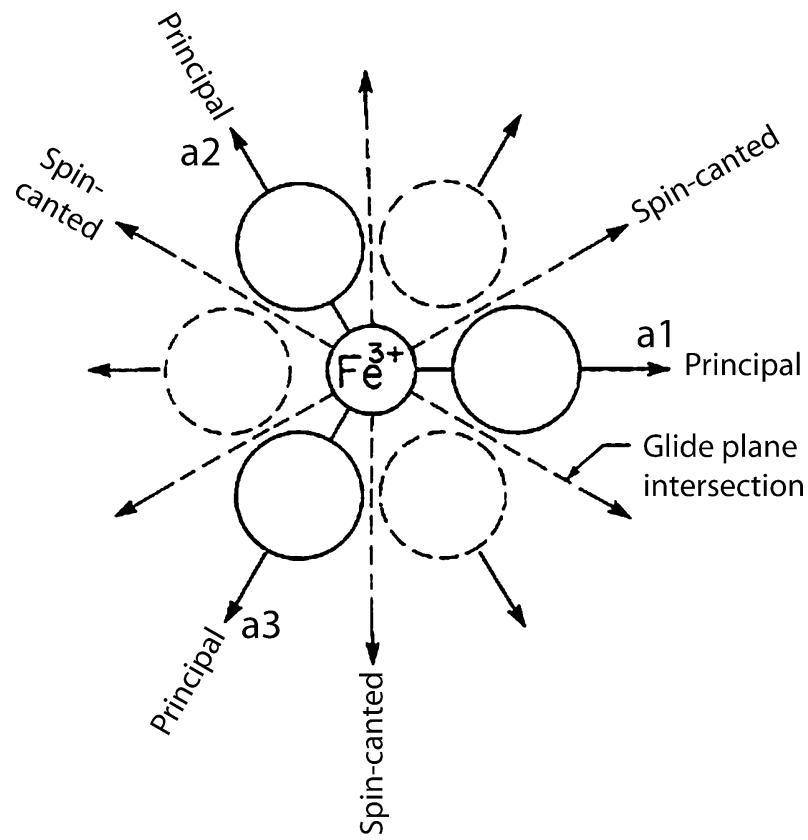

Figure 3. Relationships between crystallographic a axes and internal structure, and orientations of principal and spin-canted magnetic moment directions in the (0001) plane of haematite. Figure modified from Morrish (1994), fig. 2.5, using the data of Besser et al. (1967).

\section{HAEMO-ILMENITE SAMPLE}

\subsection{Sample description}

The coarse haemo-ilmenite sample was obtained in the main prospect pit of the Pramsknuten haemo-ilmenite dikes, a historic prospect located within the Halland-Helleren massif anorthosite, approximately $1 \mathrm{~km}$ southeast of Kydland Farm in the Egersund 1/50 000 map sheet (Krause et al. 1985; Duchesne 1999; Duchesne \& Schiellerup 2001). In hand specimen and on sawed surfaces (Fig. 4) the crystals range up to $2 \mathrm{~cm}$ in diameter and occur in an equigranular polyhedral texture. Shiny linear traces on the sawed surfaces (see especially Chips 4 and 5) appear to be due to fracturing along haematite exsolution lamellae and are consistent with the dominant lattice orientation of ilmenite as determined by electron backscatter diffraction (EBSD). Despite the isolated occurrences of trace magnetite in the Pramsknutten haemo-ilmenite, this sample was the only one available with the necessary coarse crystal size for this study.

A bulk XRF analysis from the prospect is given by Duchesne (1999) and listed in Table 2, along with our representative electron probe analyses of ilmenite host and coarse haematite exsolution lamellae. Analytical results are plotted in Fig. 5 along with published results from the finer-grained Frøytlog deposit studied in detail in an earlier paper (McEnroe et al. 2002).

\subsection{Sample preparation}

Two slices were sawed approximately normal to the horizontal top surface of the sample. A total of six chips were cut from two slices, and the top edge of each chip (see Fig. 4) was exactly parallel to the horizontal top edge of the sample, and served as the orientation key for all EBSD chips. All equal area plots of EBSD, NRM and AMS results are directly indexed to the plane of these chips with

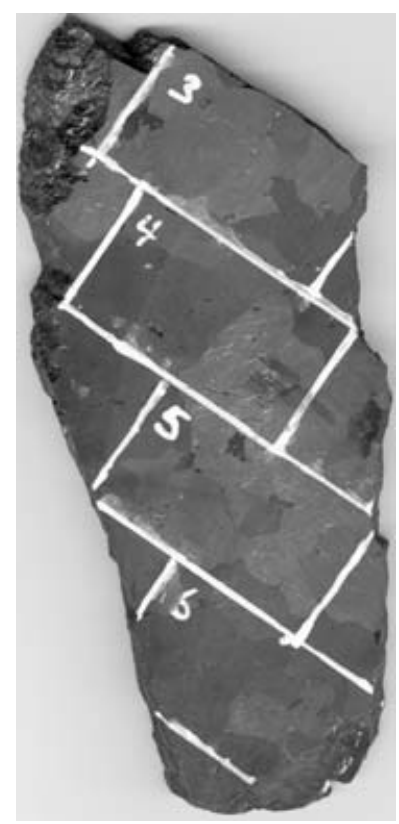

Figure 4. Scanned image of front sawed surface of coarse massive haemoilmenite from Pramsknuten showing 1-2 cm crystals and white outlines of Chips 3-6. Top edge of each chip is parallel to the top surface of the sample, which is also the top edge of Chip 3. Individual crystals are best shown on rough surfaces and are much harder to see on the polished surfaces prepared for EBSD. The bright lines trending northeast in the reference plane are shiny fractures parallel to (0001) haematite exsolution lamellae and reflect the dominant northeast-trending lattice-preferred orientation (in the reference plane) in the sample.

horizontal at the top, north to the right, south to the left and dipping $86^{\circ}$ west.

For the magnetic measurements fronts of all polished chips were scratched with a diamond scriber, making horizontal lines in the selected crystal areas parallel to the top edge of each chip, with an arrow to indicate the down direction. Crystals were extracted by cutting approximately square prisms, $\sim 6-8 \mathrm{~mm}$ on a side and $9.2-$ $12.6 \mathrm{~mm}$ tall, with a thin diamond saw. Only 17 out of an original 22 crystals could be extracted due to crowding, and some of these were of lower quality than ones lost in crowded locations. Crystals were weighed on an analytical balance, and were mounted in oriented position inside transparent $2 \mathrm{~cm}$ cubic plastic boxes for insertion into the magnetometers. Horizontal scratches on the samples were aligned parallel to horizontal plastic arrows on each box. Position of each prism along the central axis of each box was maintained by packing with cut sections of transparent plastic tubing.

\section{RESULTS}

\subsection{Electron microprobe and scanning electron microscope}

Compositional data were collected on a Cameca SX-50 electron microprobe at the Bayerisches Geoinstitut set at an accelerating potential of $20 \mathrm{keV}$, a beam current of $15 \mathrm{nA}$, and a typical beam diameter of $1 \mu \mathrm{m}$. Counting times of $30 \mathrm{~s}$ per element were used. Corrections for differential matrix effects were done using the Cameca online PAP correction routine. Analytical precision is estimated at \pm 0.1 weight per cent for oxide components present at the 1 weight 
Table 2. Bulk XRF and EMP analyses, structural formulae, end-member percentages and plotting ratios from Pramsknuten haemo-ilmenite.

\begin{tabular}{|c|c|c|c|c|c|c|c|c|}
\hline $\begin{array}{l}\text { Sample } \\
\text { mineral }\end{array}$ & $\begin{array}{c}\text { Bulk XRF } \\
\text { haemo } \\
\text {-ilmenite }\end{array}$ & $\begin{array}{r}\text { PkTrav } 25 \\
\text { ilmenite }\end{array}$ & $\begin{array}{r}\text { PkTrav } 26 \\
\text { ilmenite }\end{array}$ & $\begin{array}{r}\text { PkTrav } 27 \\
\text { ilmenite }\end{array}$ & $\begin{array}{r}\text { PkTrav } 36 \\
\text { ilmenite }\end{array}$ & $\begin{array}{r}\text { PkTrav } 38 \\
\text { ilmenite }\end{array}$ & $\begin{array}{l}\text { PkTrav } 10 \\
\text { haematite }\end{array}$ & $\begin{array}{l}\text { PkTrav } 11 \\
\text { haematite }\end{array}$ \\
\hline \multicolumn{9}{|c|}{ Wt. per cent oxides } \\
\hline $\mathrm{SiO}_{2}$ & 0.000 & 0.002 & 0.000 & 0.000 & 0.004 & 0.017 & 0.000 & 0.000 \\
\hline $\mathrm{TiO}_{2}$ & 45.800 & 53.116 & 52.707 & 53.183 & 52.821 & 52.762 & 13.330 & 13.301 \\
\hline $\mathrm{Al}_{2} \mathrm{O}_{3}$ & 0.600 & 0.000 & 0.000 & 0.000 & 0.000 & 0.002 & 0.079 & 0.079 \\
\hline $\mathrm{Cr}_{2} \mathrm{O}_{3}$ & 0.430 & 0.173 & 0.187 & 0.156 & 0.186 & 0.162 & 1.521 & 1.561 \\
\hline $\mathrm{Fe}_{2} \mathrm{O}_{3}$ & 15.923 & 4.729 & 4.883 & 4.588 & 4.879 & 4.968 & 73.561 & 73.222 \\
\hline Fe Tot & 45.820 & 41.071 & 41.115 & 41.110 & 41.155 & 41.237 & 76.189 & 76.587 \\
\hline $\mathrm{FeO}$ & 31.492 & 36.816 & 36.721 & 36.981 & 36.764 & 36.767 & 9.998 & 10.701 \\
\hline $\mathrm{MnO}$ & 0.230 & 0.266 & 0.261 & 0.221 & 0.258 & 0.258 & 0.000 & 0.000 \\
\hline $\mathrm{MgO}$ & 5.300 & 5.988 & 5.841 & 5.947 & 5.869 & 5.839 & 1.112 & 0.691 \\
\hline $\mathrm{CaO}$ & 0.000 & 0.006 & 0.000 & 0.001 & 0.007 & 0.013 & 0.004 & 0.004 \\
\hline $\mathrm{ZnO}$ & 0.014 & 0.000 & 0.000 & 0.020 & 0.009 & 0.016 & 0.000 & 0.025 \\
\hline $\mathrm{NiO}$ & 0.001 & & & & & & & \\
\hline $\mathrm{V}_{2} \mathrm{O}_{3}$ & 0.330 & 0.265 & 0.269 & 0.213 & 0.343 & 0.2825 & 0.918 & 0.937 \\
\hline Total & 98.524 & 100.886 & 100.380 & 100.851 & 100.651 & 100.5890 & 93.154 & 93.186 \\
\hline Corr. Tot. & 100.120 & 101.360 & 100.869 & 101.311 & 101.140 & 101.0868 & 100.524 & 100.522 \\
\hline \multicolumn{9}{|c|}{ Structural formulae per two cations } \\
\hline $\mathrm{Si}$ & 0.00000 & 0.00005 & 0.00000 & 0.00000 & 0.00010 & 0.00041 & 0.00000 & 0.00000 \\
\hline $\mathrm{Ti}$ & 0.83823 & 0.95333 & 0.95153 & 0.95525 & 0.95090 & 0.95053 & 0.25890 & 0.25919 \\
\hline $\mathrm{Al}$ & 0.01721 & 0.00000 & 0.00000 & 0.00000 & 0.00000 & 0.00005 & 0.00242 & 0.00242 \\
\hline $\mathrm{Cr}$ & 0.00566 & 0.00325 & 0.00355 & 0.00295 & 0.00351 & 0.00307 & 0.03107 & 0.03198 \\
\hline $\mathrm{V}$ & 0.00644 & 0.00507 & 0.00518 & 0.00408 & 0.00658 & 0.00543 & 0.01901 & 0.01947 \\
\hline $\mathrm{Fe}^{3+}$ & 0.29162 & 0.08493 & 0.08820 & 0.08247 & 0.08789 & 0.08956 & 1.42971 & 1.42777 \\
\hline $\mathrm{Mg}$ & 0.19226 & 0.21303 & 0.20899 & 0.21171 & 0.20941 & 0.20850 & 0.04283 & 0.02670 \\
\hline $\mathrm{Ni}$ & 0.00002 & & & & & & & \\
\hline Fe Total & $(0.93258)$ & $(0.81976)$ & $(0.82544)$ & $(0.82115)$ & $(0.82392)$ & $(0.82616)$ & $(1.64567)$ & $(1.65965)$ \\
\hline $\mathrm{Fe}^{2+}$ & 0.64096 & 0.73483 & 0.73724 & 0.73868 & 0.73602 & 0.73660 & 0.21595 & 0.23189 \\
\hline $\mathrm{Mn}$ & 0.00474 & 0.00538 & 0.00530 & 0.00447 & 0.00524 & 0.00524 & 0.00000 & 0.00000 \\
\hline $\mathrm{Zn}$ & 0.00025 & 0.00000 & 0.00000 & 0.00035 & 0.00015 & 0.00029 & 0.00000 & 0.00048 \\
\hline $\mathrm{Ca}$ & 0.00000 & 0.00014 & 0.00000 & 0.00004 & 0.00018 & 0.00032 & 0.00012 & 0.00012 \\
\hline Sum & 2.00000 & 2.00000 & 2.00000 & 2.00000 & 2.00000 & 2.00000 & 2.00000 & 2.00000 \\
\hline $\mathrm{Fe}^{3+} / \mathrm{FeTot}$. & 0.31270 & 0.10360 & 0.10685 & 0.10043 & 0.10668 & 0.10841 & 0.86877 & 0.86028 \\
\hline \multicolumn{9}{|c|}{ Percentages of end members } \\
\hline $\mathrm{FeSiO}_{3}$ & 0.0000 & 0.0051 & 0.0000 & 0.0000 & 0.0102 & 0.0410 & 0.0000 & 0.0000 \\
\hline $\mathrm{MgTiO}_{3}$ & 19.2258 & 21.3025 & 20.8994 & 21.1711 & 20.9413 & 20.8497 & 4.2826 & 2.6701 \\
\hline $\mathrm{NiTiO}_{3}$ & 0.0016 & & & & & & & \\
\hline $\mathrm{FeTiO}_{3}$ & 64.0961 & 73.4780 & 73.7235 & 73.8682 & 73.5921 & 73.6186 & 21.5955 & 23.1894 \\
\hline $\mathrm{MnTiO}_{3}$ & 0.4741 & 0.5377 & 0.5304 & 0.4467 & 0.5237 & 0.5240 & 0.0000 & 0.0000 \\
\hline $\mathrm{ZnTiO}_{3}$ & 0.0252 & 0.0000 & 0.0000 & 0.0351 & 0.0154 & 0.0286 & 0.0000 & 0.0476 \\
\hline $\mathrm{CaTiO}_{3}$ & 0.0000 & 0.0143 & 0.0000 & 0.0036 & 0.0179 & 0.0323 & 0.0116 & 0.0117 \\
\hline Sum & 83.8228 & 95.3377 & 95.1533 & 95.5247 & 95.1007 & 95.0944 & 25.8897 & 25.9188 \\
\hline $\mathrm{Fe}_{2} \mathrm{O}_{3}$ & 14.5810 & 4.2463 & 4.4101 & 4.1234 & 4.3947 & 4.4781 & 71.4857 & 71.3877 \\
\hline $\mathrm{Cr}_{2} \mathrm{O}_{3}$ & 0.4137 & 0.1627 & 0.1775 & 0.1477 & 0.1756 & 0.1536 & 1.5534 & 1.5988 \\
\hline $\mathrm{V}_{2} \mathrm{O}_{3}$ & 0.3220 & 0.2534 & 0.2591 & 0.2042 & 0.3290 & 0.2713 & 0.9505 & 0.9734 \\
\hline $\mathrm{Al}_{2} \mathrm{O}_{3}$ & 0.8605 & 0.0000 & 0.0000 & 0.0000 & 0.0000 & 0.0027 & 0.1208 & 0.1212 \\
\hline Sum & 16.1772 & 4.6623 & 4.8467 & 4.4753 & 4.8993 & 4.9056 & 74.1103 & 74.0812 \\
\hline Total & 100.0000 & 100.0000 & 100.0000 & 100.0000 & 100.0000 & 100.0000 & 100.0000 & 100.0000 \\
\hline \multicolumn{9}{|c|}{ Plotting ratios } \\
\hline $2 \mathrm{Ti} / *$ & 0.8382 & 0.9534 & 0.9515 & 0.9552 & 0.9510 & 0.9509 & 0.2589 & 0.2592 \\
\hline $\mathrm{Cr} / *$ & 0.0041 & 0.0016 & 0.0018 & 0.0015 & 0.0018 & 0.0015 & 0.0155 & 0.0160 \\
\hline $\mathrm{V} / *$ & 0.0032 & 0.0025 & 0.0026 & 0.0020 & 0.0033 & 0.0027 & 0.0095 & 0.0097 \\
\hline $\mathrm{Mg} / \#$ & 0.1923 & 0.2130 & 0.2090 & 0.2117 & 0.2094 & 0.2085 & 0.0428 & 0.0267 \\
\hline
\end{tabular}

$*=2 \mathrm{Ti}+\mathrm{R}^{3+} ; \#=\mathrm{R}^{2+} /\left(\mathrm{R}^{3+} / 2\right)$.

per cent level. Analytical precision on typical values of 0.5 weight per cent $\mathrm{V}_{2} \mathrm{O}_{3}$ and $\mathrm{Cr}_{2} \mathrm{O}_{3}$ is estimated to be \pm 0.06 weight per cent at the 95 per cent confidence level. In addition there is believed to be a systematic overestimate of $\mathrm{V}_{2} \mathrm{O}_{3}$ in ilmenite of about +0.1 weight per cent caused by Ti K $\beta-\mathrm{V} \mathrm{K} \alpha$ interference.
We know from previous experience that the EMP analyses closest to end members contain still finer exsolution lamellae that can only be resolved under TEM. The haemo-ilmenite bulk composition at Pramsknuten is distinctive in being richer in $\mathrm{Mg}$ and $\mathrm{Cr}$ than any other in the district. Total $\mathrm{R}^{2+} \mathrm{TiO}_{3}$ component of 83.8 per cent 


\section{Frøytlog and Pramsknuten EMP and XRF}

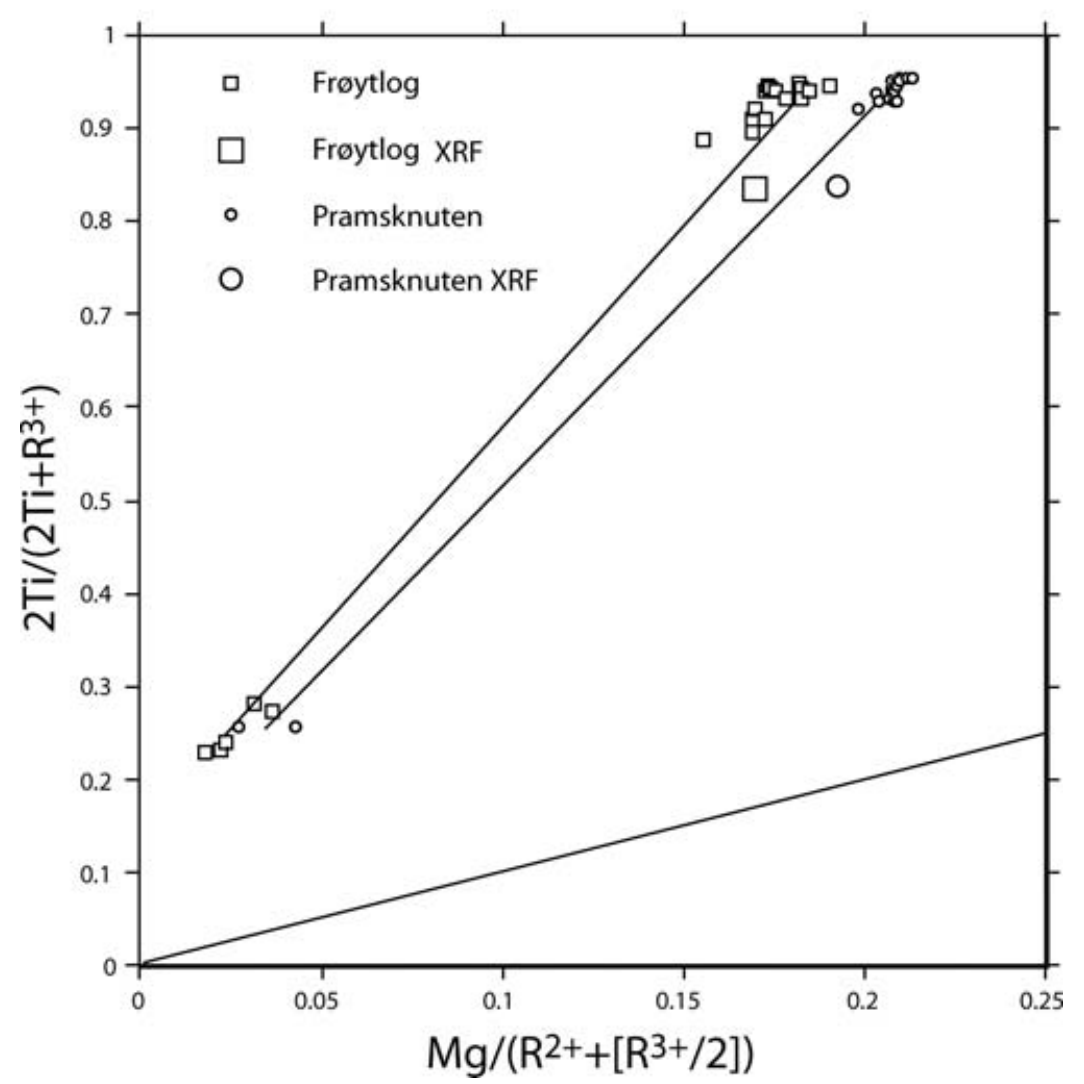

Figure 5. Plot of molar ratios $2 \mathrm{Ti} /\left(2 \mathrm{Ti}+\mathrm{R}^{3+}\right)$, proportional to $\mathrm{R}^{2+} \mathrm{TiO}_{3}$ substitution, and $\mathrm{Mg} /\left(\mathrm{R}^{2+}+\left(\mathrm{R}^{3+} / 2\right)\right.$, equivalent to $\mathrm{MgTiO}{ }_{3}$ substitution, for bulk compositions and representative EMP analyses from the Frøytlog and Pramsknuten haemo-ilmenite deposits.

includes 19.2 $\mathrm{MgTiO}_{3}, 64.1 \mathrm{FeTiO}_{3}, 0.5 \mathrm{MnTiO}_{3}$ and $0.03 \mathrm{ZnTiO}_{3}$. Total $\mathrm{R}_{2} \mathrm{O}_{3}$ component of 16.2 per cent includes $14.6 \mathrm{Fe}_{2} \mathrm{O}_{3}, 0.4$ $\mathrm{Cr}_{2} \mathrm{O}_{3}, 0.3 \mathrm{~V}_{2} \mathrm{O}_{3}$ and $0.9 \mathrm{Al}_{2} \mathrm{O}_{3}$. In five representative EMP analyses of ilmenite with minimal haematite overlap, total $\mathrm{R}^{2+} \mathrm{TiO}_{3}$ component of 95.1-95.5 per cent includes 20.9-21.3 $\mathrm{MgTiO}_{3}, 73.50-73.9$ $\mathrm{FeTiO}_{3}, 0.4-0.5 \mathrm{MnTiO}_{3}$ and $0.0-0.04 \mathrm{ZnTiO}_{3}$. Total $\mathrm{R}_{2} \mathrm{O}_{3}$ component of 4.5-4.9 per cent includes 4.1-4.5 $\mathrm{Fe}_{2} \mathrm{O}_{3}, 0.2 \mathrm{Cr}_{2} \mathrm{O}_{3}, 0.2-0.3$ $\mathrm{V}_{2} \mathrm{O}_{3}$ and $0 \mathrm{Al}_{2} \mathrm{O}_{3}$. In two EMP analyses of haematite with minimal ilmenite overlap, total $\mathrm{R}^{2+} \mathrm{TiO}_{3}$ component of 25.9 per cent includes 2.7-4.3 $\mathrm{MgTiO}_{3}, 21.6-23.2 \mathrm{FeTiO}_{3}, 0 \mathrm{MnTiO}_{3}$ and $0.0-0.05$ $\mathrm{ZnTiO}_{3}$. Total $\mathrm{R}_{2} \mathrm{O}_{3}$ component of 74.1 per cent includes 71.4-71.5 $\mathrm{Fe}_{2} \mathrm{O}_{3}, 1.6 \mathrm{Cr}_{2} \mathrm{O}_{3}, 1.0 \mathrm{~V}_{2} \mathrm{O}_{3}$ and $0.1 \mathrm{Al}_{2} \mathrm{O}_{3}$.

Like other ilmenite-haematite pairs (Robinson et al. 2001), there is a very strong fractionation of $\mathrm{Mg}$ into the ilmenite, a strong fractionation of $\mathrm{V}$ into the haematite, and an even stronger fractionation of $\mathrm{Cr}$ into the haematite, which here contains 1.6 per cent of the eskolaite end member. This compares with an extrapolated value of 0.6 per cent eskolaite in haematite exsolution for the most primitive haemo-ilmenite composition we have measured in the Tellnes Deposit (McEnroe et al. 2001b; Robinson et al. 2001). The $\mathrm{Al}_{2} \mathrm{O}_{3}$ shown by the bulk analysis is poorly reflected in the probe analyses, suggesting small inclusions, probably of spinel, in the bulk-analysed material (Duchesne \& Schiellerup 2001, p. 74). The 25 per cent of $\mathrm{R}^{2+} \mathrm{TiO}_{3}$ component in the haematite represents a composition achieved in early exsolution of $\mathrm{R} \overline{3} \mathrm{c}$ haematite from $R \overline{3}$ ilmenite at a temperature above the eutectoid reaction $R \overline{3} c$ PM haematite $=$
CAF haematite $+R \overline{3}$ PM ilmenite that permits the development of lamellar magnetism (McEnroe et al. 2002; Robinson et al. 2002, 2004). The eutectoid temperature in the pure $\mathrm{FeTiO}_{3}-\mathrm{Fe}_{2} \mathrm{O}_{3}$ system has been variously estimated at $390^{\circ} \mathrm{C}$ and $520^{\circ} \mathrm{C}$ (see discussion, McEnroe et al. 2004a, 2005).

Despite prior petrologic reports to the contrary (Duchesne 1999), magnetic properties, particularly susceptibility and demagnetization, suggested the presence of very small amounts of magnetite in some crystals that may distort the geometrical relationships. Work in reflected light and qualitative scanning electron microscope (SEMEDS) analyses on part of Chip 4 confirmed three types of minor magnetite occurrences (1) as small blades associated with haematite lamellae in fresh haemo-ilmenite, (2) as part of minor secondary alteration zones associated with fractures where ilmenite-haematite had reacted at low temperature to magnetite-rutile-Mg silicate and (3) as blebs exsolved from primary aluminous spinel blebs. SEM showed several discrete grains of the rare oxide srilankite, $\mathrm{ZrTi}_{2} \mathrm{O}_{6}$, the second occurrence recorded in Norway (Bingen et al. 2001). The dispersed blades of magnetite ( 1 above) may be a response to a cooling reaction by which scarce baddeleyite $\left(\mathrm{ZrO}_{2}\right)$ and intermediate haematite-ilmenite solid solution reacted to form srilankite + magnetite. However, baddeleyite also occurs in direct contact with ilmenite.

Detailed transmitted-light examination of the small isolated patches not consisting of opaque oxides showed apparently fresh spinel and baddeleyite, cloudy srilankite, and a very fine-grained 
mesh of variegated chlorite and serpentine minerals replacing all the expected silicates. This suggestion of a retrograde metamorphism could be coupled with the formation of fine magnetite and consistent with the position of the locality some $35 \mathrm{~km}$ southeast of the Silurian-Devonian Caledonide Front as compared to $50 \mathrm{~km}$ or more for occurrences with fresh silicates we have studied previously. It is also consistent with demagnetization studies of oriented bulk samples from the same location, and may be an indication of how extremely stable the haemo-ilmenite is in preserving the original Mesoproterozoic magnetization.

\subsection{Electron backscatter diffraction}

The principal of electron backscattering diffraction (EBSD) in the SEM has been known for over 50 yr (Alam et al. 1954), but only recently has become a widespread technique for the measurement of crystal orientations in bulk samples (e.g. Adams et al. 1993). The method is based on the fact that backscattered electrons undergo multiple scattering inside the sample and form a diffraction pattern consisting of lines and bands equivalent to the well known Kikuchi diffraction patterns in TEM. If the electron beam in the SEM is focussed on a single crystal underneath the sample surface, its diffraction pattern can be recorded and indexed if the crystal structure is known. The generation of the diffraction pattern is almost instantaneous, and one pattern is sufficient to determine the complete crystallographic orientation. Recent uses of EBSD involving oxide minerals include the study by Bascou et al. (2002) on the relation between bulk titanohaematite lattice-preferred orientation and anisotropy of magnetic susceptibility in mylonites, and by Feinberg et al. (2004) on the relationships between lattice orientations of magnetite exsolution lamellae and their clinopyroxene hosts. Here we used it to determine the locations and the exact orientations of crystallographic a and $\mathbf{c}$ axes of relatively coarse haemo-ilmenite crystals as the first step to investigate their magnetic properties.

The electron backscattering pattern (EBSP) is formed in a very thin surface layer $(<1 \mu \mathrm{m})$, and for this reason it is strongly affected by standard polishing techniques, which introduce damage to the crystalline lattice in the polished surface. To assure that the EBSD is reflecting the natural crystallographic orientation in the samples, the damaged layer was removed by additional polishing with a high$\mathrm{pH}$ silica solution (40 $\mathrm{nm}$ particle size) for several hours (SYTON polish, Fynn 1979). Finally the sample surface was coated with a few nanometers of carbon to reduce charging in the SEM.

The SEM used in this study was a Leo Gemini 1530 with a Schottky emitter as electron source. Conditions for producing EBSPs from the ilmenite crystals were $20 \mathrm{keV}$ acceleration voltage and a beam current of about $4 \mathrm{nA}$ (120 $\mu \mathrm{m}$ aperture) at a working distance of $18 \mathrm{~mm}$. For the recording and indexing of the EBSP's the system CHANNEL of HKLTechnology was used.

Table 3. Orientation data for 17 haemo-ilmenite crystals from electron back-scatter diffraction. $\mathrm{D}=\mathrm{Declination}$ is taken clockwise from $\mathrm{N}$ on the reference circle; $\mathrm{I}=$ Inclination which is given negative for upper hemisphere.

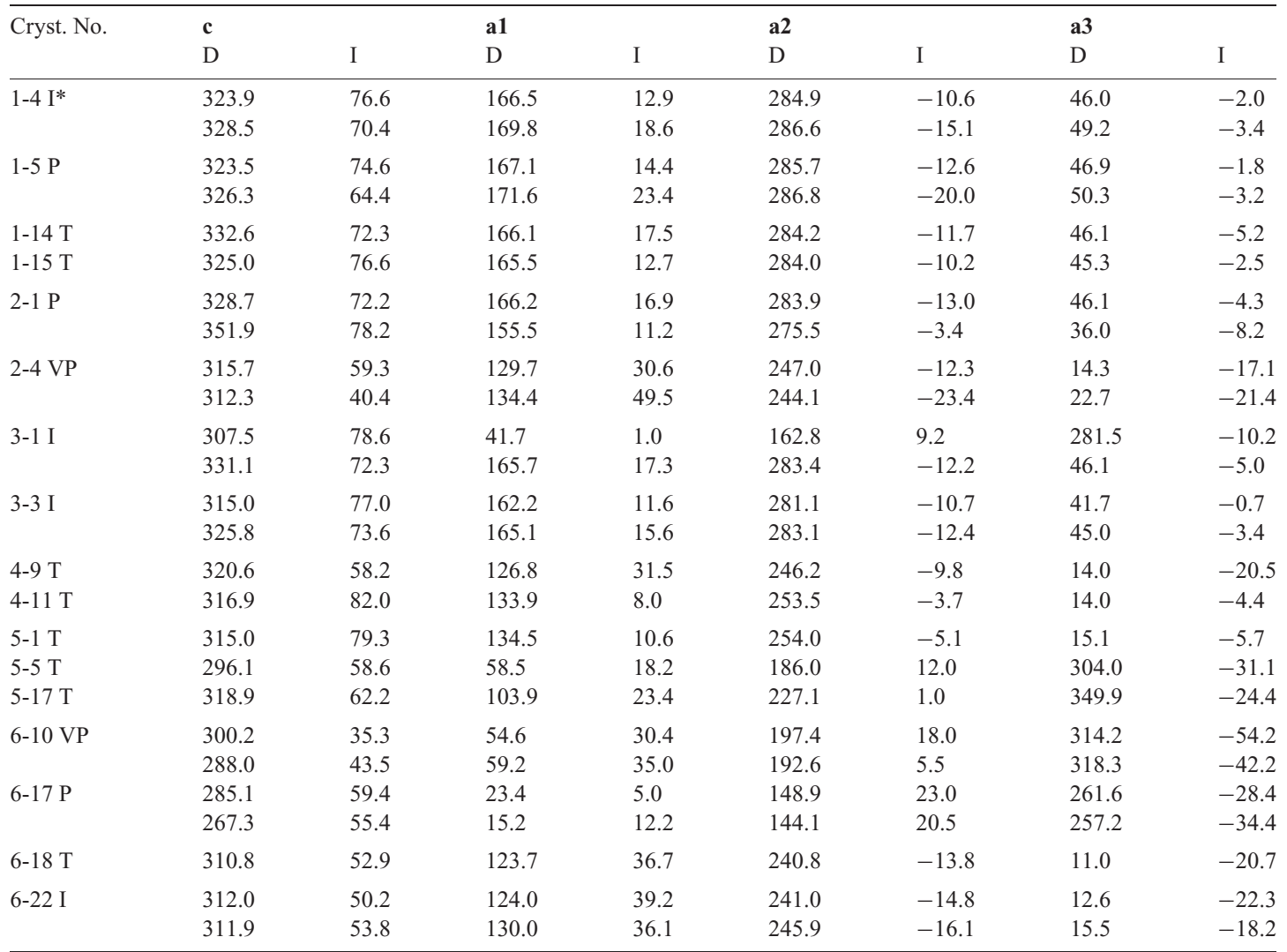

${ }^{\star}$ Quality of fit between front and back polished surfaces based on visual inspection of plotted results. Accuracy of measurement is probably better than $\pm 2^{\circ} . \mathrm{T}=$ top, no difference between front and back measurements; $\mathrm{I}=$ intermediate, some measurable difference between front and back measurements which are listed separately beneath; $\mathrm{P}=$ poor, striking difference between front and back measurements; VP = very poor, very large difference between front and back measurements. 
An EBSP is generated from a rather small crystal volume of about $1 \mu \mathrm{m}^{3}$ or less, which is quite small compared to the size of the investigated crystals. Therefore, the method provides no information about the orientation spread between the upper and lower surfaces of the chips. However, although it is possible to probe the orientation changes within individual crystals in the sample surface by moving the beam, we found that the orientation remained generally rather constant $\left(<1^{\circ}\right.$ orientation difference).

Table 3 lists the declinations and inclinations of the crystallographic c, a1, a2, and $\mathbf{a 3}$ axes for the 17 crystals. Accuracy of the measurement is $\pm 2^{\circ}$. In labelling the a axes, a1 was chosen arbitrarily as the first axis encountered in moving clockwise around the basal plane in the lower hemisphere from its intersection with the reference circle. $\mathbf{a} \mathbf{2}$ and $\mathbf{a} \mathbf{3}$ are then encountered in continuing clockwise on the basal plane and either one or two of these occur in the upper hemisphere noted by a negative inclination. Each crystal in Table 3 is marked by a letter T, I, P or VP (see footnote in Table 3) indicating the quality of fit between front and back polished surfaces based on plotted results.

Fig. 6 is an equal area diagram on which are plotted all of the measured crystallographic axes of the individual crystals, indexed to the reference plane. There are 26 plotted crystallographic $\mathbf{c}$ axes including eight from quality group $\mathrm{T}$ with identical front and back measurements, and 18 from quality groups I, P and VP with different front and back surface measurements. The $\mathbf{c}$ axes are nearly all in the northwest quadrant, indicating southeast-dipping (0001) basal planes with respect to the reference plane, and that the sample has quite a strong uniaxial lattice-preferred orientation (LPO). The crystallographic a axes within the basal planes show less obvious LPO, but there are some systematic groupings and the distribution is clearly non-random.

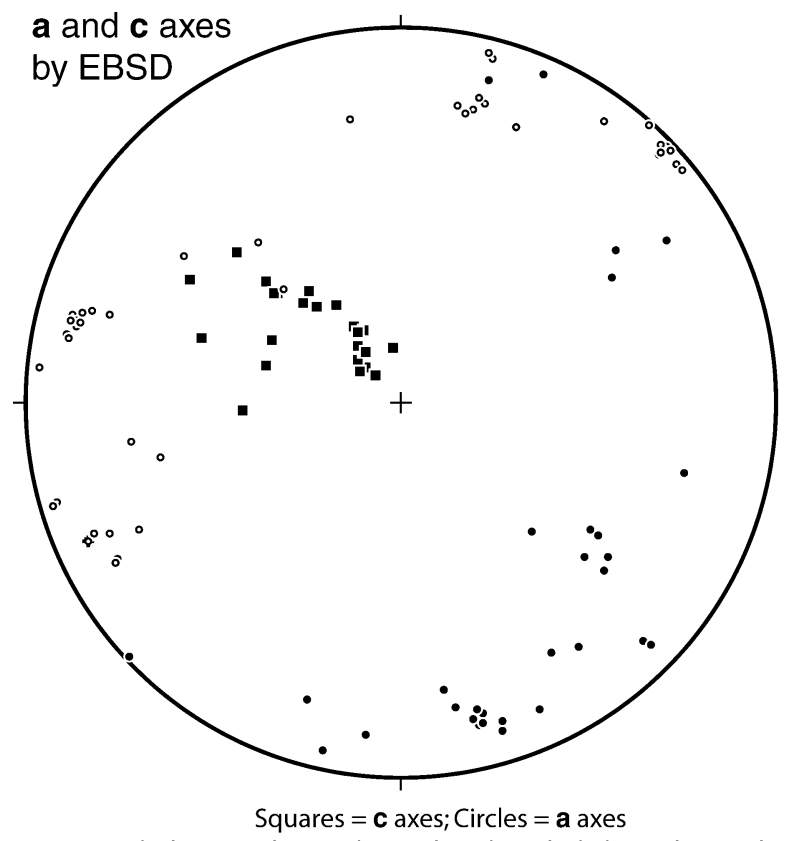

Open symbols: upper hemisphere; Closed symbols: lower hemisphere

Figure 6. Equal area diagrams of all ilmenite crystals measured, illustrating the haemo-ilmenite lattice-preferred orientation (LPO) of the sample. Orientations of 26 crystallographic $\mathbf{c}$ axes, all on bottom hemisphere, and their corresponding crystallographic a axes are shown.

\subsection{Bulk magnetic susceptibility}

Susceptibility measurements on the 17 haemo-ilmenite crystals were made inside their mounting boxes at ETH Zurich. Susceptibilities were calculated from geometric means of the AMS measurements and crystal weight. These results are listed by crystal in Table 4 along with crystal weight. Mass susceptibility values range from 1.91 to $9.84 \times 10^{-3} \mathrm{~m}^{3} \mathrm{~kg}^{-1}$, with a mean of $3.38 \times$ $10^{-3} \mathrm{~m}^{3} \mathrm{~kg}^{-1}$. Excluding the value for sample 6-10 VP, the range is much narrower at $1.91-5.15 \times 10^{-3} \mathrm{~m}^{3} \mathrm{~kg}^{-1}$ with a mean of $2.97 \times$ $10^{-3} \mathrm{~m}^{3} \mathrm{~kg}^{-1}$, similar to other well studied haemo-ilmenite samples (McEnroe et al. 2002).

\subsection{Natural remanent magnetization}

The NRMs of crystals were first measured on a 3-axis, 2G cryogenic magnetometer (Model 755) at the University of Massachusetts (UMASS) and then in the Laboratory of Natural Magnetism (LNM) at the ETH-Zurich. The crystals were measured using a singleposition procedure at UMASS, and a three- and six-position procedure to check on the homogeneity of the magnetization at the LNM (Lowrie et al. 1980). Selected crystals were remeasured with a 24-position procedure to check if sample shape may influence the remanence measurement. No systematic effect could be detected. All methods gave the same result within the circular standard deviation calculated from the six-measurement procedure (Table 5). NRM intensities were generally between 0.5 and 4.7 per cent higher for the measurements made at UMASS.

Weight-normalized NRM ranges from 1.4 to $9.1 \times$ $10^{-3} \mathrm{Am}^{2} \mathrm{~kg}^{-1}$, with a mean of $4.2 \times 10^{-3} \mathrm{Am}^{2} \mathrm{~kg}^{-1}$ and a rather even distribution except near the top of the range. However

Table 4. Crystal weights, mass susceptibilities, and NRMs for haemoilmenite crystals.

\begin{tabular}{llll}
\hline 1 & 2 & 3 & 4 \\
Crystal & $\begin{array}{l}\text { Crystal } \\
\text { wt. g }\end{array}$ & $\begin{array}{l}\mathrm{k}^{1} \\
\mathrm{~m}^{3} \mathrm{~kg}^{-1}\end{array}$ & $\begin{array}{l}\mathrm{M} \times 10^{-3} \\
\mathrm{Am}^{2} \mathrm{~kg}^{-1}\end{array}$ \\
No. & 2.7815 & $2.54 \mathrm{E}-06$ & 7.814 \\
\hline $1-4 \mathrm{I}(\mathrm{C})^{2}$ & 4.0811 & $3.49 \mathrm{E}-06$ & 9.085 \\
1-5 P (B) & 2.8572 & $3.85 \mathrm{E}-06$ & 8.112 \\
1-14 T (D) & 2.4479 & $3.22 \mathrm{E}-06$ & 6.304 \\
1-15 T (B) & 2.6216 & $1.91 \mathrm{E}-06$ & 3.964 \\
2-1 P (D) & 2.5904 & $2.05 \mathrm{E}-06$ & 4.417 \\
2-4 VP (C) & 1.1092 & $2.18 \mathrm{E}-06$ & 4.148 \\
3-1 I (B) & 2.1153 & $3.56 \mathrm{E}-06$ & 4.091 \\
3-3 I (B) & 1.6664 & $5.15 \mathrm{E}-06$ & 2.957 \\
4-9 T (A) & 1.1730 & $2.71 \mathrm{E}-06$ & 4.956 \\
4-11 T (A) & 1.9770 & $2.26 \mathrm{E}-06$ & 2.613 \\
5-1 T (A) & 1.4719 & $4.70 \mathrm{E}-06$ & 1.438 \\
5-5 T (C) & 1.5817 & $2.34 \mathrm{E}-06$ & 1.484 \\
5-17 (T) (B) & 0.9706 & $9.84 \mathrm{E}-06$ & 1.526 \\
6-10 VP (D) & 1.4611 & $2.10 \mathrm{E}-06$ & 2.178 \\
6-17 P (A) & 2.3253 & $2.10 \mathrm{E}-06$ & 3.180 \\
6-18 T (D) & 1.7868 & $3.39 \mathrm{E}-06$ & 3.235 \\
6-22 I (A) &
\end{tabular}

${ }^{1}$ Mass susceptibility of each crystal given is the geometric mean of the mass susceptibilities k1, k2, k3 listed in Table 7.

${ }^{2}$ First letter following crystal number is a subjective estimate of quality based on similarity of EBSD results front and back of polished chip (see notes for Table $3: \mathrm{T}=$ top, $\mathrm{I}=$ intermediate, $\mathrm{P}=$ poor, $\mathrm{VP}=$ very poor. Second letter (A-D) is an overall geometrical classification of the grain based on angular relationships between the NRM and crystallographic axes as listed in Table 6. 
Table 5. Declinations and inclinations of NRM vectors and weightnormalized NRM intensities for all 17 crystals. Declination and inclination are reported with reference to EBSD circle with 0 declination at top and inclinations ' + ' for lower hemisphere and '-' for upper hemisphere.

\begin{tabular}{lllll}
\hline Crystal No. & Declination & Inclination & $\begin{array}{l}\mathrm{M} \times 10^{-3} \\
\mathrm{Am}^{2} \mathrm{~kg}^{-1}\end{array}$ & $\begin{array}{l}\text { Circular } \\
\text { std. deviation }\end{array}$ \\
\hline 1-4 I* & 192.0 & +9.7 & 7.814 & 2.2 \\
1-5 P & 189.5 & +22.9 & 9.085 & 2.7 \\
1-14 T & 192.8 & -1.7 & 8.112 & 2.0 \\
1-15 T & 33.7 & -11.7 & 6.304 & 2.0 \\
2-1 P & 124.0 & +37.4 & 3.964 & 4.4 \\
2-4 VP & 86.4 & +44.7 & 4.417 & 2.3 \\
3-1 I & 151.9 & +7.7 & 4.148 & 2.9 \\
3-3 I & 145.3 & +11.4 & 4.091 & 2.6 \\
4-9 T & 132.6 & +33.1 & 2.957 & 2.2 \\
4-11 T & 143.2 & +10.7 & 4.956 & 2.6 \\
5-1 T & 130.4 & +16.0 & 2.613 & 2.5 \\
5-5 T & 152.5 & +13.8 & 1.438 & 2.8 \\
5-17 T & 118.0 & +29.7 & 1.484 & 2.2 \\
6-10 VP & 225.1 & -67.3 & 1.526 & 2.7 \\
6-17 P & 141.4 & +22.3 & 2.178 & 2.4 \\
6-18 T & 151.7 & +13.9 & 3.180 & 2.3 \\
6-22 I & 124.0 & +39.7 & 3.235 & 2.3 \\
\hline
\end{tabular}

*Letter following crystal number is a subjective estimate of quality based on similarity of EBSD results front and back of polished chip (see notes for Table 3 ): $\mathrm{T}=$ top, $\mathrm{I}=$ intermediate, $\mathrm{P}=$ poor, $\mathrm{VP}=$ very poor.

the top four NRM values, 6.3 to $9.1 \times 10^{-3} \mathrm{Am}^{2} \mathrm{~kg}^{-1}$ all come from crystals taken from Chip 1, which have special orientations of the NRM (Fig. 7). The peculiar aspect of these crystals is shown in an alternating field demagnetization experiment on Crystal 1-4, discussed briefly below, and in detail in a later paper. Aside from these, the range is 1.4 to $4.2 \times 10^{-3} \mathrm{Am}^{2} \mathrm{~kg}^{-1}$. The dominant NRM direction is southeasterly in terms of the reference plane, with inclinations $8^{\circ}-40^{\circ}$ from crystals taken from chips 3-6, which come from slice 2 (Fig. 4) and chip 2 from slice 1. Crystals from chip 1, which is from slice 1 , had south-southwesterly or northeasterly declinations and flat inclinations (Fig. 7). Crystals 2-4VP and 6-10VP deviate from the other crystals.

Fig. 8 illustrates in equal area diagrams for each crystal, the angular relationships between crystallographic a and $\mathbf{c}$ axes measured by EBSD, and NRM vectors. These are re-classified as A, B, C and D, according to the relationship between the magnetic parameters and the crystallographic axes (Table 6). The NRM from samples in Class A lies in basal plane of the haemo-ilmenite crystal and its direction is within $10^{\circ}$ of an a axis (Table 6). In Class B the NRM lies in basal plane but its direction is only within $20^{\circ}$ from an a axis. In Class $C$ the NRM lies in or near the basal plane but the remanence direction is $20^{\circ}-35^{\circ}$ from an a axis, thus coming closest to the angle of $30^{\circ}$ indicated for spin-canted magnetization of haematite. In the final Class D, the NRM lies $15^{\circ}$ or more from the basal plane and $30^{\circ}$ or more from an a axis. Some crystals rated T from EBSD data, do not show very rational combined correlations and fall in Class D, whereas others rated I or P from EBSD are in Class A with very good correlations. All this angle data and the four classes of crystals are shown together in Fig. 9.

A question that inevitably arises is the extent to which the NRM is influenced by the very small amount of magnetite in some samples. Some samples, for example 1-4, suspected to contain magnetite, were AF demagnetized and showed removal of a soft component by $10 \mathrm{mT}$, that we think is carried by magnetite. By $10 \mathrm{mT}$ the vector had

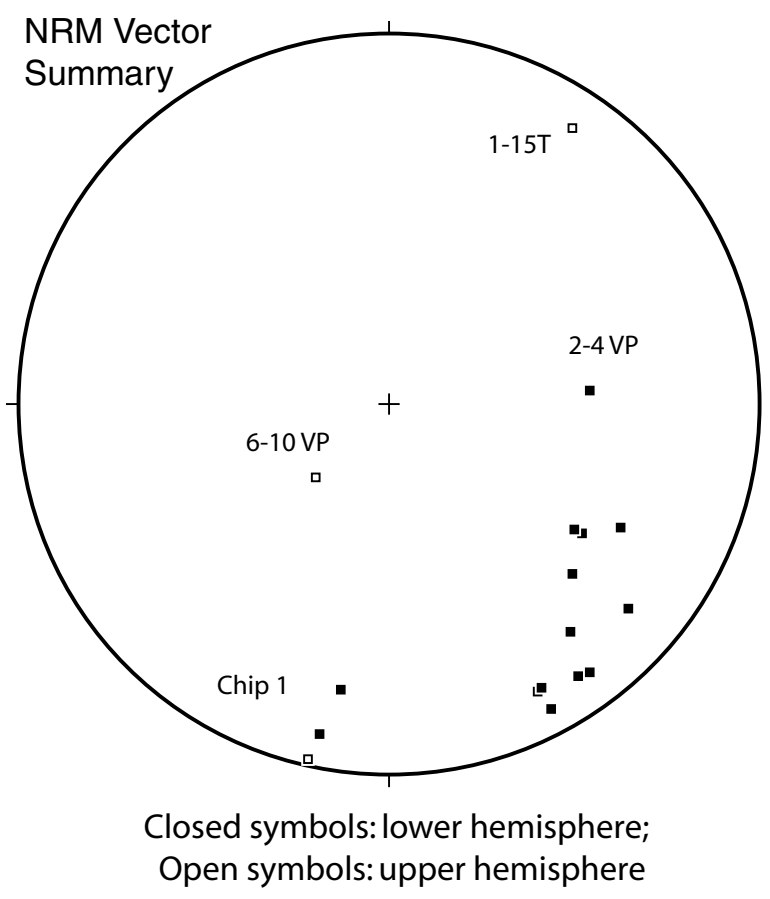

Figure 7. Equal area diagram showing NRM vectors from all 17 crystals in Table 5 .

rotated from the southwest quadrant of Fig. 7 into the predominant grouping of other NRM vectors in the southeast quadrant where it remained through $170 \mathrm{mT}$, the highest field that was applied.

\subsection{Anisotropy of magnetic susceptibility}

The AMS is the directional variability of the magnetic susceptibility (ki). Mathematically it is described as a symmetric tensor of second rank, and is represented geometrically as an ellipsoid with three principal axes, $\mathrm{k} 1 \geq \mathrm{k} 2 \geq \mathrm{k} 3$. The low-field magnetic anisotropy was measured on an AGICO KLY2 susceptibility bridge, which applies a field of $300 \mathrm{~A} \mathrm{~m}^{-1} .15$ independent measurements are made to determine the susceptibility magnitude ellipsoid (Jelinek 1978). Hrouda (2002) pointed out that the low-field susceptibility of haematite as measured on the KLY-2 may not be within the range of the Rayleigh law. However, although magnitudes of the principal axes may be overestimated, the ellipsoid shape and orientation of the principal axes can be precisely determined. Results are listed in Table 7. Orientations of the $\mathrm{k} 3$ axes are plotted in Fig. 8, and angular relationships between crystallographic $\mathbf{c}$ axes and NRM vectors, and the $\mathrm{k} 3$ axes are listed for each crystal in Table 8.

A question that arises in consideration of AMS results, is the extent of influence on results from the shape of the sample prisms. As seen in Fig. 8 and Table 8, the low-field AMS generally lies near to the crystallographic $\mathbf{c}$ axis of the haemo-ilmenites as determined from EBSD. Thus, any shape effect is not strong enough to overcome the dominating AMS of this rhombohedral oxide, with minimum susceptibility approximately in the c-axis direction.

The orientations of $\mathrm{k} 3$ ellipsoid axes can be compared with the collective crystallographic orientations determined by EBSD (Fig. 8). Not surprisingly, the overall correlation between $\mathrm{k} 3$ and $\mathbf{c}$-axis orientations is strong, also between NRM directions and the k1 - k2 basal plane. The $\mathrm{k} 3$ axis of the AMS ellipsoid is generally within $10^{\circ}$ of the c-crystallographic axes (Table 8). Exceptions include sample 

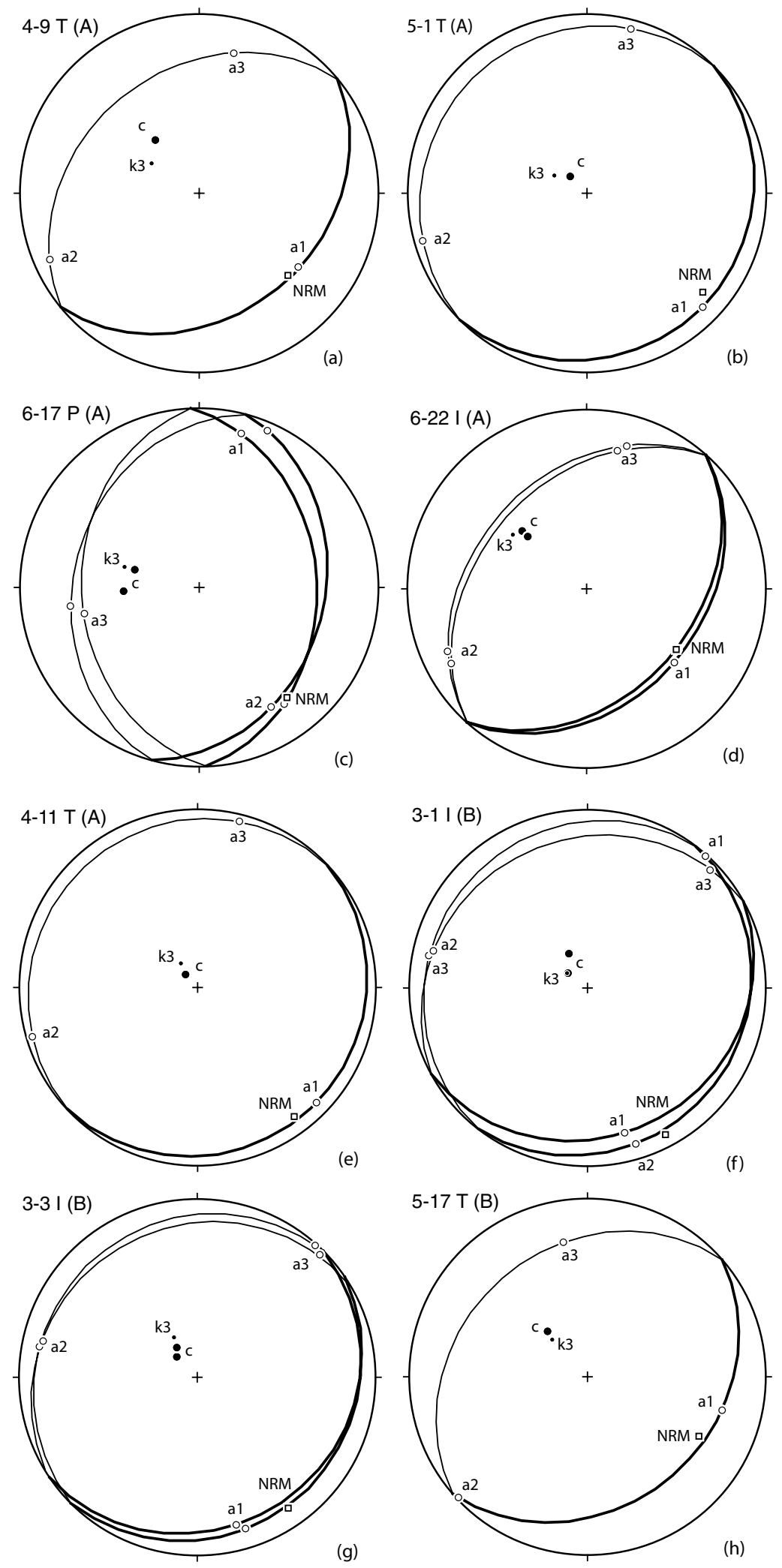

Figure 8. Equal area diagrams showing relationships between crystallographic axes determined by EBSD, NRM vectors, and k3 axes of the AMS. Crystallographic (0001) planes are shown bold in lower hemisphere, normal in upper hemisphere. NRM vectors in the upper hemisphere are indicated 'u.h.'. (a-e) Five crystals in Class A. (f-j) Five crystals in Class B. (k-m) Three crystals in Class C. (n-q) Four crystals in Class D. 

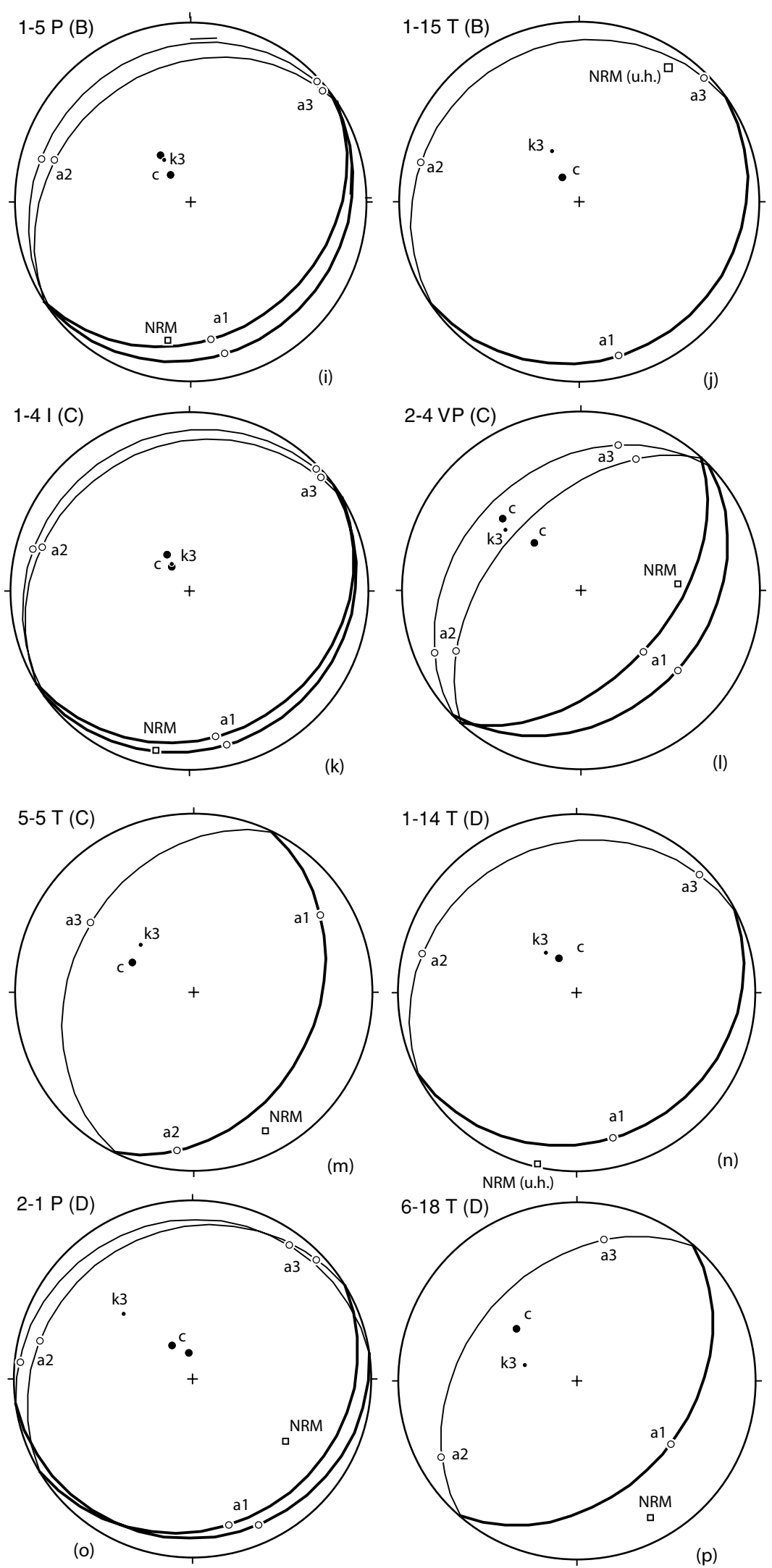

Figure 8. (Continued.) 


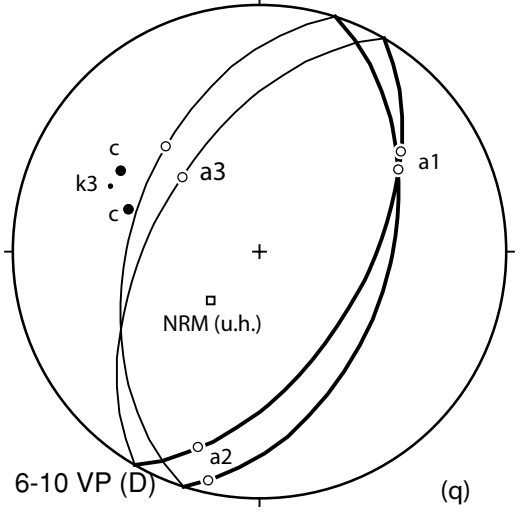

Figure 8. (Continued.)

1-15 in Class B, and 2-1 and 6-18 in Class D. Correlations within the basal plane between a-axis orientations, NRM orientations, and $\mathrm{k} 2$ and $\mathrm{k} 1$ axis orientations are more diverse and more complex, and are the subject of a later paper.

\section{DISCUSSION}

As stated above, EBSD only measures the crystallographic orientation at the surface, whereas the AMS is a bulk property of the sample. Several crystals that showed a poor agreement between the orientation of the $\mathbf{c}$ axis from the front and the back, show that the $\mathrm{k} 3$ axis is in good agreement with one of the orientations. Therefore, in these cases, we assume that bulk of the crystal is controlled by the one orientation (Tables 5 and 8), and angular measurements from the part of the crystal that agrees less with the AMS are marked by italics in Table 6.

Standard relationships of AMS ellipsoids of haematite and the fact that the NRM is considered ideally to lie in the $\mathrm{k} 1-\mathrm{k} 2$ plane, mean that ideally the angle between the $\mathrm{k} 3$ axis and the NRM should be $90^{\circ}$. Thus, ideally these results should be more representative of the material as a whole, except to the extent that the AMS or the NRM orientations are biased by sample shape. Table 8 lists the angle between the NRM and $\mathrm{k} 3$ axes of the AMS ellipsoid, which should be $90^{\circ}$ in the ideal case. The $\mathrm{k} 3$ axis for 14 of the 17 crystals is $80^{\circ}$ or more from the NRM direction. Thus, taking into account the measurement error of the NRM direction and error in the fit of the AMS ellipsoid, 14 of the 17 crystals fulfil this observation. One of the crystals that does not fulfil this criterion is 6-10 VP. This is the smallest of the crystals with by far the highest susceptibility, which convinces us that it contains magnetite. All the crystals from Chip 1 are peculiar in showing an NRM in the southwest or northeast quadrant. Based on the alternating field demagnetization experiment on 1-4 I, the unusual NRM orientations in the Chip 1 crystals very likely relate to minor magnetite.

The five crystals in Class A illustrated in Fig. 8(a-e) are nearly ideal in most respects. Not only does the direction of the NRM plot very close to the basal (0001) plane, with maximum deviation of $6.1^{\circ}$, but it plots very close to a crystallographic a axis within the basal plane, with a maximum deviation of $8.9^{\circ}$ (Fig. 9). This is true even for crystal 6-17 P, where the front and back EBSD basal plane orientations are quite different. The NRM directions are also at least $82^{\circ}$ away from the $\mathrm{k} 3$ axes (Table 8 ). These five crys-
Table 6. Angular relationships between crystallographic axes measured by EBSD, and NRM vectors. For each crystal, the NRM vector has been combined with one or two EBSD crystallographic measurements, yielding one or two angles. Where two angles are given, the measurement from the crystal side with the poorer agreement between $\mathrm{c}$ and $\mathrm{k} 3$ (Table 8) is shown in italics.

\begin{tabular}{|c|c|c|}
\hline Cryst. No. & $\mathrm{NRM} \wedge(0001)^{1}$ & $\mathrm{NRM} \wedge \mathbf{a}^{2}$ \\
\hline $4-9 \mathrm{~T}(\mathrm{~A})^{3}$ & 2.3 & 5.5 \\
\hline $5-1 \mathrm{~T}(\mathrm{~A})$ & 6.1 & 6.8 \\
\hline \multirow[t]{2}{*}{ 6-17 P (A) } & 2.4 & 7.0 \\
\hline & 0.6 & 2.9 \\
\hline \multirow[t]{2}{*}{ 6-22 I (A) } & 0.5 & 0.5 \\
\hline & 4.1 & 5.4 \\
\hline 4-11 T (A) & 3.7 & 8.9 \\
\hline \multirow[t]{2}{*}{ 3-1 I (B) } & 1.7 & 10.9 \\
\hline & 8.1 & 16.8 \\
\hline \multirow[t]{2}{*}{ 3-3 I (B) } & 3.0 & 19.7 \\
\hline & 0 & 17.0 \\
\hline 5-17 T (B) & 0.6 & 13.0 \\
\hline \multirow[t]{2}{*}{$1-5 \mathrm{P}(\mathrm{B})$} & 4.1 & 17.0 \\
\hline & 12.7 & 23.7 \\
\hline $1-15 \mathrm{~T}(\mathrm{~B})$ & 6.1 & 14.8 \\
\hline \multirow[t]{2}{*}{ 1-4 I (C) } & 1.6 & 25.0 \\
\hline & 4.3 & 22.5 \\
\hline \multirow[t]{2}{*}{ 2-4 VP (C) } & 5.5 & 32.4 \\
\hline & 22.5 & 36.0 \\
\hline $5-5 \mathrm{~T}(\mathrm{C})$ & 11.4 & 32.5 \\
\hline $1-14 \mathrm{~T}$ (D) & 15.7 & 31.7 \\
\hline \multirow[t]{2}{*}{ 2-1 P (D) } & 21.5 & 42.4 \\
\hline & 30.2 & 38.6 \\
\hline 6-18 T (D) & 19.7 & 34.0 \\
\hline \multirow[t]{2}{*}{ 6-10 VP (D) } & 26.7 & 41.5 \\
\hline & 30.2 & 53.2 \\
\hline
\end{tabular}

${ }^{1} \mathrm{NRM} \wedge(0001)$ indicates the amount the NRM direction differs from the basal (0001) plane as determined by EBSD. Ideally for haematite, the NRM direction should lie in the basal plane.

${ }^{2} \mathrm{NRM} \wedge \mathrm{a}$ indicates the amount the NRM direction differs from the nearest a-crystallographic axis within the basal plane. Ideally the NRM should lie in the basal plane. According to the postulates of lamellar magnetism, the NRM direction should have a very small angle with an a-axis and not an angle of $30^{\circ}$, which would be theoretically characteristic of spin-canted haematite.

${ }^{3}$ First letter following crystal number is a subjective estimate of quality based on similarity of EBSD results front and back of polished chip (see notes for Table 3): $\mathrm{T}=$ top, $\mathrm{I}=$ intermediate, $\mathrm{P}=$ poor, $\mathrm{VP}=$ very poor. Second letter $(\mathrm{A}-\mathrm{D})$ is an overall geometrical classification of the grain based on angular relationships between the NRM and crystallographic axes listed here (see text)

tals fulfil all of the theoretical characteristics expected for lamellar magnetism.

The five crystals in Class B, illustrated in Figs $8(\mathrm{f}-\mathrm{j})$ and 9, are slightly less ideal than those in Class A. If we rule out the part of the crystals, where the c axis disagrees more with the $\mathrm{k} 3$ axis of the AMS (Table 5), then in all five the NRM plots very close to the basal (0001) plane, with maximum deviation of $6.1^{\circ}$. However, the NRMs do not plot so close to a crystallographic a axis within the basal plane, but at angles ranging from $10.9^{\circ}$ to $19.7^{\circ}$. In all, the 


\section{Comparison of NRM vs. Crystallography}

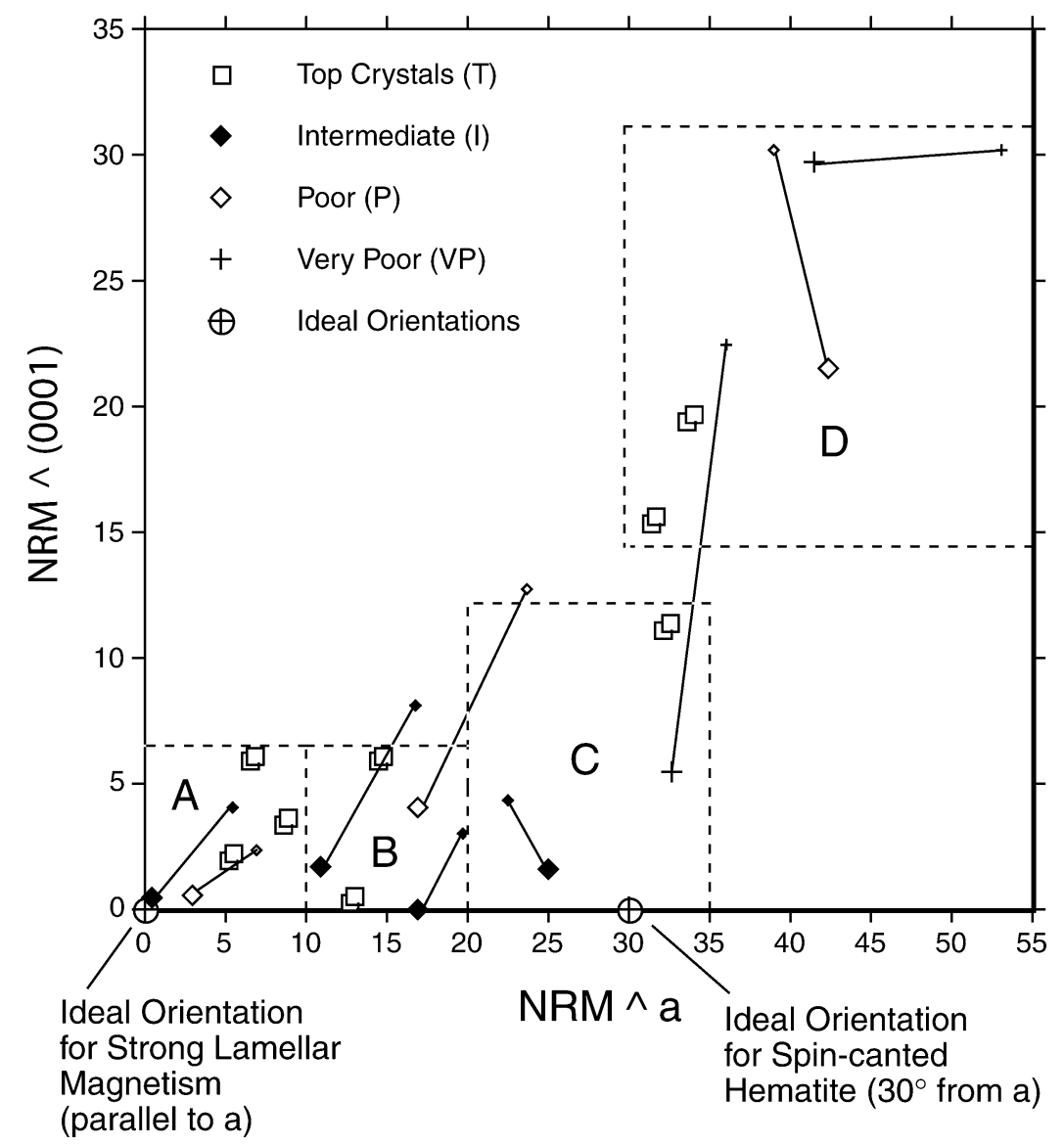

Figure 9. Plot of the angles NRM $\wedge(0001)$ vs. $N R M \wedge$ a, providing evidence for or against the lamellar magnetism hypothesis. NRM $\wedge(0001)$ indicates the amount the NRM direction differs from the basal (0001) plane as determined by EBSD. NRM $\wedge$ a indicates the amount the NRM direction differs from the nearest crystallographic a axis. Symbols represent different quality groups based on EBSD results with T crystals indicated with double symbols to indicate perfect overlap of front and back readings. Thin lines join different front and back orientation measurements from a single crystal—the larger symbol in each pair indicating best agreement with the NRM. Outlined areas A, B, C, D indicate the four quality classes of crystals (see Table 6). The plot shows a concentration approaching NRM $\wedge(0001)=0^{\circ}$ and NRM $\wedge \boldsymbol{a}=0^{\circ}$, and a lack of concentration at NRM $\wedge(0001)=0$ and $\mathrm{NRM} \wedge \boldsymbol{a}=30^{\circ}$.

NRM direction is $80^{\circ}$ or more away from the $\mathrm{k} 3$ axis (Table 8 ). These five crystals fulfil the theoretical characteristics for lamellar magnetism slightly less successfully, nevertheless none reaches the theoretical value of $30^{\circ}$ in the basal plane to be expected for spincanted magnetism of haematite. Possibly these results reflect the spin-canted aspect of moderate to weak lamellar magnetism.

The three crystals of Class C in Figs $8(\mathrm{k}-\mathrm{m})$ and 9 have an NRM direction that is within $11.4^{\circ}$ of the basal plane and 22.5 to $32.5^{\circ}$ from a crystallographic a axis (Table 6). These three crystals can be taken to support a spin-canted magnetization, though the clustering around the ideal direction in Fig. 9 is far weaker than is the clustering for Class A. The NRM is more than $82^{\circ}$ away from the $\mathrm{k} 3$ axes for samples $1-4$ and 2-4 (Table 8 ), but $73.8^{\circ}$ away in sample 5-5.

The NRM directions from the four crystals in Class D shown in Figs $8(n-q)$ and 9 deviate more than $15^{\circ}$ from the basal plane of the haemo-ilmenite (Table 6). The angle between the NRM direction and $\mathrm{k} 3$, however, is very high in $2-1$, and $6-18$, but low in crystals 1-14 and 6-10 (Table 8). In crystal 6-10 VP, the NRM lies at a steep angle in the upper hemisphere far away from the basal plane or any a axis.

\section{CONCLUSIONS}

The coincidence of the NRM orientation with a crystallographic a axis in the basal plane in many of the rhombohedral haemo-ilmenite crystals investigated here, is in agreement with the theory of lamellar magnetism. This theory indicates that the principal magnetic moment of lamellar magnetism should be parallel to the direction of principal magnetic moments (sublattice magnetizations) in the oxide layers. Earlier studies of Besser et al. (1967) show that such principal magnetic moments in the rhombohedral oxide haematite are oriented parallel to a crystallographic a axis in the basal (0001) plane. By contrast the NRM orientations are generally inconsistent with spin-canted magnetism of haematite in which the spin-canted moments, according to Besser et al. (1967), would be normal to a crystallographic a axis in the basal (0001) plane or 30 degrees from an adjacent crystallographic a axis. In some of the haemoilmenite crystals, the NRM is not aligned with a crystallographic a axis, with angles that deviate up to 20 degrees. These may be examples of spin-canted lamellar magnetism, in which the NRM orientation is produced by relatively weak, considerably 'out-of-phase' lamellar magnetism. The latter may be conceived as a compromise 
Table 7. List of AMS intensities and ellipsoid axial orientations for each haemo-ilmenite single crystal. $\mathrm{k}=$ mass susceptibility; $\mathrm{D}=$ declination, and I = inclination of principal AMS ellipsoid axes relative to EBSD reference plane.

\begin{tabular}{llrrrrrrrr}
\hline Cryst. no. & k1 & D & I & k2 & D & I & k3 & D & I \\
\hline 1-4 I* (C) & $4.01 \mathrm{E}-06$ & 224.5 & 3.3 & $2.53 \mathrm{E}-06$ & 133.6 & 14.4 & $1.62 \mathrm{E}-06$ & 327.1 & 75.2 \\
1-5 P (B) & $4.69 \mathrm{E}-06$ & 216.6 & 8.2 & $3.50 \mathrm{E}-06$ & 123.4 & 21.1 & $2.60 \mathrm{E}-06$ & 326.7 & 67.2 \\
1-14 T (D) & $5.75 \mathrm{E}-06$ & 213.0 & 8.1 & $4.05 \mathrm{E}-06$ & 119.8 & 21.2 & $2.46 \mathrm{E}-06$ & 322.7 & 67.1 \\
1-15 T (B) & $4.51 \mathrm{E}-06$ & 234.8 & 3.2 & $3.32 \mathrm{E}-06$ & 143.2 & 26.0 & $2.24 \mathrm{E}-06$ & 331.4 & 63.8 \\
2-1 P (D) & $2.57 \mathrm{E}-06$ & 43.3 & 0.1 & $2.06 \mathrm{E}-06$ & 133.4 & 44.0 & $1.33 \mathrm{E}-06$ & 313.2 & 46.0 \\
2-4 VP (C) & $2.66 \mathrm{E}-06$ & 40.3 & 1.3 & $2.28 \mathrm{E}-06$ & 131.5 & 44.9 & $1.43 \mathrm{E}-06$ & 309.0 & 45.0 \\
3-1 I (B) & $3.02 \mathrm{E}-06$ & 46.2 & 2.2 & $2.47 \mathrm{E}-06$ & 136.6 & 11.3 & $1.39 \mathrm{E}-06$ & 305.3 & 78.5 \\
3-3 I (B) & $5.22 \mathrm{E}-06$ & 220.1 & 7.6 & $3.88 \mathrm{E}-06$ & 127.4 & 19.6 & $2.23 \mathrm{E}-06$ & 330.4 & 68.9 \\
4-9 T (A) & $8.59 \mathrm{E}-06$ & 49.2 & 8.1 & $4.68 \mathrm{E}-06$ & 142.8 & 24.2 & $3.35 \mathrm{E}-06$ & 301.9 & 64.3 \\
4-11 T (A) & $3.69 \mathrm{E}-06$ & 217.3 & 4.5 & $3.17 \mathrm{E}-06$ & 126.3 & 12.6 & $1.71 \mathrm{E}-06$ & 326.4 & 76.6 \\
5-1 T (A) & $2.94 \mathrm{E}-06$ & 41.6 & 3.7 & $2.38 \mathrm{E}-06$ & 132.7 & 16.4 & $1.66 \mathrm{E}-06$ & 299.1 & 73.1 \\
5-5 T (C) & $9.240 \mathrm{E}-06$ & 50.8 & 5.7 & $4.64 \mathrm{E}-06$ & 144.3 & 31.9 & $3.13 \mathrm{E}-06$ & 311.7 & 57.5 \\
5-17 T (B) & $3.35 \mathrm{E}-06$ & 218.6 & 3.5 & $2.48 \mathrm{E}-06$ & 127.1 & 23.1 & $1.53 \mathrm{E}-06$ & 316.7 & 66.6 \\
6-10 VP (D) & $1.31 \mathrm{E}-05$ & 200.1 & 5.4 & $1.07 \mathrm{E}-05$ & 102.3 & 55.2 & $6.77 \mathrm{E}-06$ & 293.7 & 34.3 \\
6-17 P (A) & $2.67 \mathrm{E}-06$ & 45.4 & 19.8 & $2.21 \mathrm{E}-06$ & 146.5 & 28.2 & $1.57 \mathrm{E}-06$ & 285.1 & 54.4 \\
6-18 T (D) & $2.73 \mathrm{E}-06$ & 39.5 & 9.9 & $2.35 \mathrm{E}-06$ & 133.6 & 22.5 & $1.44 \mathrm{E}-06$ & 287.2 & 65.2 \\
6-22 I (A) & $4.95 \mathrm{E}-06$ & 42.6 & 5.8 & $3.57 \mathrm{E}-06$ & 137.9 & 41.8 & $2.21 \mathrm{E}-06$ & 306.2 & 47.6 \\
\hline
\end{tabular}

*First letter following crystal number is a subjective estimate of quality based on similarity of EBSD results front and back of polished chip (see notes for Table 3: $\mathrm{T}=$ top, $\mathrm{I}=$ intermediate, $\mathrm{P}=$ poor, $\mathrm{VP}=$ very poor. Second letter $(\mathrm{A}-\mathrm{D})$ is an overall geometrical classification of the grain based on angular relationships between the NRM and crystallographic axes listed in Table 6 .

vector sum of lamellar magnetism plus a contribution from spincanted haematite. The conformity of NRM orientations to relationships predicted for the rhombohedral oxides in most crystals, shows that they dominate the magnetism, in spite of the minor amount of magnetite observed microscopically, predicted from susceptibilities, and demonstrated by demagnetization experiments to be reported in detail elsewhere.

When the anisotropy of magnetic susceptibility was applied to these crystals, most showed a very small angle between the crystallographic $\mathbf{c}$ axis and the $\mathrm{k} 3$ axis of susceptibility, generally consistent with the known strong anisotropy of haematite and ilmenite. Furthermore, many showed an NRM at close to 90 degrees from the $\mathrm{k} 3$ axis of the AMS, again confirming the location of the NRM in the k1-k2 basal plane. In addition, most crystals showed a pronounced basal plane anisotropy of the AMS, which is the subject of another paper. Experiments involving further investigation of the AMS, torque, alternating-field demagnetization, atomic-force microscopy and neutron scattering are in progress to learn more about the behaviour of these crystals.

\section{ACK N OWLEDGMENTS}

This project was begun 2002-2003 while PR was a visiting scientist at Australian Research Council Key Centre for Geochemical Evolution and Metallogeny of Continents (GEMOC), Department of Earth and Planetary Sciences, Macquarie University, New South Wales, Australia, and SAM was a visiting scientist at CSIRO Exploration and Mining, North Ryde, New South Wales, Australia. The late Rob Hargraves provided strong encouragement and lively discussion on this subject. EBSD work at Bayerisches Geoinstitut was supported under the EU Research Infrastructures Transnational Access Programme (Contract No. 505320 (RITA)-High Pressure). This work was supported by a Norwegian Research Council Grant to SAM (163556/S10). Henrik Schiellerup provided qualitative EDS analyses on the SEM at NGU. Access to thin diamond saws was provided by the Thin Section Lab at Macquarie University and Prof. Stephen
Burns at University of Massachusetts. Polishing required for EBSD work was done by Hubert Schultze. The manuscript benefited greatly from reviews provided by Mike Fuller and Mike Jackson. To each of these persons and institutions we express our grateful acknowledgement. ETH Contribution Nr. 1426.

\section{REFERENCES}

Adams, B.L., Wright, S.I. \& Kunze, K., 1993. Orientation imaging: the emergence of a new microscopy, Metal. Trans., 24A, 819-833.

Alam, M.N., Blackman, M. \& Pashley, D.W., 1954. High-angle Kikuchi patterns, Roy. Soc. London Proc., 221, 224-242.

Bascou, J., Raposo, M.I.B., Vauchez, A. \& Egydio-Silva, M., 2002. Titanohematite lattice-preferred orientation and magnetic anisotropy in high-temperature mylonites, Earth Planet. Sci. Lett., 198, 77-92.

Besser, P.J., Morrish, A.H. \& Searle, C.W., 1967. Magnetocrystalline anisotropy of pure and doped hematite, Phys. Rev., 153, 632-640.

Bingen, B., Davis, W.J. \& Austrheim, H., 2001. Zircon U-Pb geochronology in the Bergen arc eclogites and their Proterozoic protoliths, and implications for the pre-Scandian evolution of the Caledonides in western Norway, Geol. Soc. Am. Bull., 113, 640-649.

Duchesne, J-C., 1999. Fe-Ti deposits in Rogaland anorthosites (South Norway): geochemical characteristics and problems of interpretation, Mineralium Deposita, 34, 182-198.

Duchesne, J-C. \& Schiellerup, H., 2001. The iron-titanium deposits, in Duchesne, J-C., ed. The Rogaland Intrusive Massifs- an excursion guide, NGU (Geological Survey of Norway) Report 2001.29, 56-75.

Dzialoshinskii, I., 1958. A thermodynamic theory of 'weak' ferromagnetism of antiferromagnetics, J. Phys. Chem. Sol., 4, 241-255.

Feinberg, J.M., Wenk, H.-R., Renne, P.R. \& Scott, G.R., 2004. Epitaxial relationships of clinopyroxene-hosted magnetite determined using electron backscatter diffraction (EBSD) technique, Am. Min., 89, 462-466.

Fynn, G.W. \& Powell, W.J.A., 1979. The Cutting and Polishing of Electrooptical Materials, 2nd edn, 230 pp., Bristol, GBR, Adam Hilger.

Harrison, R.J., 2006. Microstructure and magnetism in the ilmenite-hematite solid solution: a Monte Carlo simulation study, Am. Min., in press.

Harrison, R.J. \& Becker, U., 2001. Magnetic ordering in solid solutions, Europ. Min. U. Notes Min., 3, 349-383. 
Table 8. Table of angular measurements between crystallographic c axes measured by EBSD or the NRM, and k3 axes of the AMS. If there are two EBSD surface measurements, the angle showing poorer agreement with $\mathrm{k} 3$ is shown in italics.

\begin{tabular}{|c|c|c|}
\hline Cryst. no. & $\mathbf{c} \wedge \mathrm{k} 3^{1}$ & $\mathrm{NRM} \wedge \mathrm{k} 3^{2}$ \\
\hline $4-9 \mathrm{~T}(\mathrm{~A})^{3}$ & 10.5 & 82.4 \\
\hline 5-1 T (A) & 7.2 & 89.3 \\
\hline \multirow[t]{2}{*}{ 6-17 P (A) } & 5.2 & 82.8 \\
\hline & 10.0 & \\
\hline \multirow{2}{*}{ 6-22 I (A) } & 4.6 & 86.9 \\
\hline & 7.1 & \\
\hline 4-11 T (A) & 6.1 & 87.0 \\
\hline \multirow[t]{2}{*}{ 3-1 I (B) } & 0 & 87.6 \\
\hline & 8.8 & \\
\hline \multirow[t]{2}{*}{ 3-3 I (B) } & 5.0 & 80.2 \\
\hline & 9.2 & \\
\hline 5-17 T (B) & 4.5 & 83.1 \\
\hline \multirow[t]{2}{*}{$1-5 \mathrm{P}(\mathrm{B})$} & 3.0 & 84.1 \\
\hline & 7.3 & \\
\hline $1-15 \mathrm{~T}$ (B) & 13.1 & 89.0 \\
\hline \multirow[t]{2}{*}{ 1-4 I (C) } & 1.7 & 89.5 \\
\hline & 4.3 & \\
\hline \multirow[t]{2}{*}{ 2-4 VP (C) } & 5.1 & 82.4 \\
\hline & 14.8 & \\
\hline $5-5 \mathrm{~T}(\mathrm{C})$ & 8.6 & 73.8 \\
\hline $1-14 \mathrm{~T}$ (D) & 6.2 & 72.7 \\
\hline \multirow[t]{2}{*}{ 2-1 P (D) } & 27.3 & 83.9 \\
\hline & 35.1 & \\
\hline 6-18 T (D) & 16.7 & 86.0 \\
\hline \multirow[t]{2}{*}{ 6-10 VP (D) } & 5.0 & 66.1 \\
\hline & 10.4 & \\
\hline
\end{tabular}

$\overline{{ }^{1} \mathbf{c} \wedge \mathrm{k} 3 \text { is the acute angle measured on a great circle between a }}$ c-crystallographic axis determined by EBSD and the $\mathrm{k} 3$ axis of the AMS ellipsoid. For ideal haematite these directions should coincide. Deviations from zero can be interpreted as an index of how the AMS ellipsoid, a bulk measurement of the entire sample, deviates from crystallographic results obtained on front and back polished surfaces.

${ }^{2} \mathrm{NRM} \wedge \mathrm{k} 3$ is the acute angle measured on a great circle between the NRM vector and the absolute orientation of the minimum axis of the AMS ellipsoid. In the ideal theoretical case for haematite, the NRM vector should lie in the basal (0001) plane, which should be the $\mathrm{k} 1=\mathrm{k} 2$ plane of the AMS ellipsoid, hence normal to the $\mathrm{k} 3$ axis. Thus, for ideal haematite, $\mathrm{NRM} \wedge \mathrm{k} 3$ should be $90^{\circ}$.

${ }^{3}$ First letter following crystal number is a subjective estimate of quality based on similarity of EBSD results front and back of polished chip (see notes for Table 3 :

$\mathrm{T}=$ top, $\mathrm{I}=$ intermediate, $\mathrm{P}=$ poor, $\mathrm{VP}=$ very poor. Second letter (A-D) is an overall geometrical classification of the grain based on angular relationships between the NRM and crystallographic axes listed in Table 6 .
Hrouda, F., 2002. Low-field variation of magnetic susceptibility and its effect on the anisotropy of magnetic susceptibility of rocks, Geophys. J. Inter, 150, 715-723.

Jelinek, V., 1978. Statistical processing of magnetic susceptibility measured on groups of specimens, Stud. Geophys. Geod., 22, 50-62.

Kasama, T., McEnroe, S.A., Ozaki, N., Kogure, T. \& Putnis, A., 2004. Effects of nanoscale exsolution in hematite-ilmenite on the acquisition of stable natural remanent magnetization. Earth Planet. Sci. Lett., 224, 461475.

Krause, H., Gierth, E. \& Schott, W., 1985. Fe-Ti deposits in the south Rogaland igneous complex, especially in the anorthosite massif of Ana-Sira, NGU Bulletin, 402, 25-37.

Lowrie, W., Channell, J.E.T. \& Heller, F., 1980. On the credibility of paleomagnetic measurements, Geophys. J. R. Astr. Soc., 60, 493-496.

McEnroe, S.A. \& Brown, L.L., 2000. A closer look at remanence-dominated aeromagnetic anomalies: rock-magnetic properties and magnetic mineralogy of the Russell Belt microcline-sillimanite gneiss, Northwest Adirondack Mountains, New York, J. Geophys. Res., 105, 16 437-16456.

McEnroe, S.A., Harrison, R.J., Robinson, P., Golla, U. \& Jercinovic, M.J., 2001a. The effect of fine-scale microstructures in titanohematite on the acquisition and stability of NRM in granulite facies metamorphic rocks from Southwest Sweden: implications for crustal magnetism, J. Geophys. Res., 106, 30 523-30 546.

McEnroe, S.A., Robinson, P. \& Panish, P.T., 2001b. Aeromagnetic anomalies, magnetic petrology and characterization of ilmenite-and magneticrich cumulates of the Sokndal region, Rogaland, Norway, Am. Min., 86, $1447-1468$.

McEnroe, S.A., Harrison, R.J., Robinson, P. \& Langenhorst, F., 2002. Nanoscale haematite-ilmenite lamellae in massive ilmenite rock: an example of 'Lamellar Magnetism' with implications for planetary magnetic anomalies, Geophys. J. Inter., 151, 890-912.

McEnroe, S.A. Langenhorst, F., Robinson, P., Bromiley G. \& Shaw, C., 2004a. What's magnetic in the lower Crust? Earth Planet. Sci. Lett., 226, 175-192.

McEnroe, S.A., Skilbrei, J.R., Robinson, P., Heidelbach, F., Langenhorst, F. \& Brown, L.L. 2004b. Magnetic anomalies, layered intrusions and Mars, Geophys. Res. Lett., 31, L19601, doi:10.1029/2004GL020640.

McEnroe, S.A. et al., 2005. Lamellar magnetism: effects of interface versus exchange interactions of nanoscale exsolutions in the ilmenite-hematite system, J. Phys. Conf. Ser., 17, 154-167.

Morrish, A.H., 1994. Canted Antiferromagnetic Hematite, World Scientific Publishing Co. Ltd., Singapore, 173 pp.

Robinson, P., Panish, P.T. \& McEnroe, S.A., 2001. Minor element chemistry of haemo-ilmenite- and magnetite-rich cumulates from the Sokndal region, south Rogaland, Norway, Am. Min., 86, 1469-1476.

Robinson, P., Harrison, R.J., McEnroe, S.A. \& Hargraves, R.B., 2002. Lamellar magnetism in the haematite-ilmenite series as an explanation for strong remanent magnetization, Nature, 418, 517-520.

Robinson, P., Harrison, R.J., McEnroe, S.A. \& Hargraves, R.B., 2004. Nature and origin of lamellar magnetism in the hematite-ilmenite series, Am. Min., 89, 725-747.

Robinson, P., Harrison, R.J. \& McEnroe, S.A., 2006. $\mathrm{Fe}^{2+} / \mathrm{Fe}^{3+}$ charge ordering in contact layers of lamellar magnetism: bond valence arguments, Am. Min., 91, 67-72. 